\title{
SOBRE LA CRÍTICA DE KELSEN AL MARXISMO
}

1

\section{Introducción}

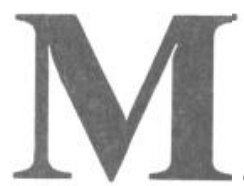

ario G. Losano ha caracterizado el conjunto de los trabajos en los que Kelsen fue construyendo y desarrollando la teoría pura del Derecho como un opus perpetuum en los tres sentidos siguientes: en primer lugar, en el de monumentum aere perennius de la cultura jurídica; en segundo, en el de perpeutum mobile, esto es, indicando su carácter «de teoría en continua transformación»; por último, aludiendo a que se trata de una «obra intrínsecamente unitaria a través del tiempo, aunque fragmentada, por exigencias contingentes, en ensayos, libros y reediciones»! .

Si partimos de la consideración (probablemente indiscutible por su misma trivialidad) de que el marxismo y las diversas críticas a él dirigidas -desde que, a finales del XIX, sufriera su primera «crisis»- constituyen uno de los ejes principales en el desarrollo de las ciencias sociales del último siglo, no nos será difícil concordar en atribuir también a los trabajos kelsenianos sobre Marx y los marxistas la calificación de opus perpetuum en el primero de los sentidos señalados por Losano: esto es, valorarlos como un monumentum aere perennius del pensamiento social contemporáneo. Pues la crítica de Kelsen al marxismo -que se extiende a lo largo de cuatro decenios, desde Socialismo y Estado (1. a ed.: 1920) hasta, por lo menos, La teoría

M. G. Losano: La teoría pura del Derecho del logicismo al irracionalismo, en «Doxa. Cuadernos de Filosofía del Derecho», n. ${ }^{\circ} 2$ 2, 1985, pp. 55 y 57. Este trabajo de Losano se publicó originalmente como estudio preliminar a la trad. italiana de la obra póstuma de Kelsen Allgemeine Theorie der Normen (Teoria generale delle norme, ed. de M. G. Losano, trad. de Mirella Torre, Einaudi, Torino, 1985).

2 Las principales obras de Kelsen directamente dirigidas a la crítica del marxismo se citan así:

-Sozialismus und Staat. Eine Untersuchung der politischen Theorie des Marxismus (1. ${ }^{a}$ ed.: 1920; 2. ${ }^{a}$ ed. ampliada -esencialmente con notas críticas al libro de Max Adler Die Staatsauffassung des Marxismus, publicado en 1922, que a se vez era una respuesta a la primera edición de Sozialismus und Staat, 1923) por la traducción castellana de Alfonso García Ruiz de la 2. ${ }^{a}$ edición: Socialismo y Estado: Una investigación sobre la teoría política del marxismo, con una introducción de R. Racinaro sobre Hans Kelsen y el debate sobre democracia y parlamentarismo en los anos veinte y treinta, Siglo XXI, México, 1982 (la introducción de Racinaro se publicó originalmente como estudio preliminar a la trad. italiana de Sozialismus und Staat: De Donato, Bari, 1978). Hay otra reciente trad. castellana de Sozialismus und Staat a cargo de Rolf Behrman, con una presentación de Enrique Zuleta Puceiro: Edersa, Madrid, 1985.

-Marx oder Lassalle. Wandlungen in der politischen Theorie des Marxismus (1924) por la trad. castellana -Marx o Lassalle. Cambios en la teoría política del marxismopublicada como apéndice a la trad. cast. de Sozialismus und Staat de Alfonso García Ruiz citada.

-Allgemeine Rechtslehre im Lichte materialistischer Geschichtsauffassung (1931) por la traducción italiana de Francesco Riccobono: La teoria generale del Diritto e il 
comunista del Derecho (1955) ${ }^{2}$ - es con seguridad sólo comparable, en cuanto a su importancia, con la de Popper, a la que por cierto se anticipa -como se tendrá ocasión de ver- en varios puntos centrales. Y, a este respecto, el que el autor de La miseria del historicismo (1944-1945) y La sociedad abierta y sus enemigos (1945) no parezca haber entrado en contacto con la obra previa de Kelsen sobre el marxismo y el que, a la inversa, este último no muestre, en sus trabajos sobre el tema de las décadas 40/50, ningún conocimiento de los textos de Popper, es ciertamente una manifestación bien elocuente de la incomunicación que ha venido tradicionalmente separando a los teóricos del Derecho de los cultivadores de otras ramas de la teoría social. Como también es altamente significativo, en este orden de cosas, el que mientras los trabajos de Popper sobre el marxismo han gozado de una difusión amplísima -hasta el punto de que al menos su existencia es conocida por cualquier cultivador de cualquier rama de las ciencias sociales- los correspondientes escritos kelsenianos no hayan sido más que raramente leídos fuera del universo de los juristas ${ }^{3}$.

Pero si los trabajos de Kelsen sobre la teoría pura del Derecho pueden ser calificados de opus perpetuum también en el segundo de los sentidos indicados, en el de perpetuum mobile -pues, en efecto, el andamiaje conceptual de la teoría pura fue enriqueciéndose mediante desarrollos, integraciones y rectificaciones durante los sesenta años que separan los Problemas capitales de la teoría del Derecho público de La teoría general de las normas ${ }^{4}$ - de ninguna manera puede decirse otro tanto de la obra kelseniana sobre el marxismo. Muy al contrario, en este terreno parece como si casi todo lo que de importancia Kelsen tuviera que decir lo hubiera dicho ya en sus obras fundamentales sobre el tema de los años 20 y 30: Socialismo y Estado y La teoría general del Derecho y el materialismo histórico. Frente a ellas, los textos de los años 40/50 -La teoría política del bolchevismo, La teoría comunista del Derecho- pese al carácter indudablemente más completo del segundo de ellos por lo que hace a las teorías jurídicas marxistas, no contienen aportaciones propiamente novedosas y presentan, como ha se-

materialismo storico, con introducción al mismo Riccobono, Istituto della Enciclopedia Italiana, Roma, 1979.

-The Political Theory of Bolchevism. A Critical Analysis. (1948) y The Communist Theory of Law (1955) por la trad. castellana conjunta de ambas obras a cargo de Alfredo J. Weiss publicada con el título de Teoría Comunista del Derecho y del Estado, Emecé Ediciones, Buenos Aires, 1957.

3 Y, aun dentro de los juristas, no deja de ser sintomático que Alf Ross, en el parágrafo de Sobre el Derecho y la justicia dedicado a El historicismo económico de Marx, en el que formula críticas reconducibles sin dificultad a Kelsen, no cite sin embargo en su apoyo los escritos kelsenianos de crítica del marxismo, sino única y precisamente a Popper (Alf Ross: Sobre el Derecho y la justicia, trad. cast. de G. R. Carrió, Eudeba, Buenos Aires, 1970, pp. 336-339).

4 Hautprobleme der Staatrechtslehre se publicó, como se sabe, en 1911. La redacción del manuscrito de la Allgemeine Theorie der Normen, publicada póstumamente en 1979, no se prolongó, según los datos disponibles, más allá de la segunda mitad de los años sesenta (cfr. Mario G. Losano: Op. cit. en nota 1 y Kasimierz Opalek: Uberlegungen zu Hans Kelsen «Allgemeine Theorie der Normen», Manz, Wien, 1980). 
ñalado F. Riccobono, «un estilo repetitivo y sin viveza» ${ }^{5}$. A ello probablemente no es ajena la circunstancia de que la relación entre la crítica del marxismo y la propia teoría kelseniana del Derecho sea muy distinta en uno y otro período: en las obras de los años 20/30 la crítica del marxismo constituye, como ha indicado el mismo Riccobono ${ }^{6}$, un momento esencial en la construcción misma de la teoría pura -que se encuentra entonces in statu nascendi- y un excepcional banco de pruebas de su fecundidad; los textos de los años 40/50 -período en el que la teoría pura se encuentra plenamente constituida desde tiempo atrás- se encuentran carentes de esa tensión intelectual que viene a ser el mayor atractivo de Socialismo y Estado y, sobre todo, de La teoría general del Derecho y el materialismo histórico. Salvado esto -y ciertas diferencias en las actitudes del propio Kelsen que examinaremos seguidamente- las críticas filosóficas, teórico-políticas y teóricojurídicas que Kelsen dirige al marxismo permanecen, en uno y otro período, globalmente invariables, no sólo en cuanto a su fondo, sino también, en una multiplicidad de ocasiones, en su misma expresión literal: lo que hace, desde luego, de la crítica kelseniana al marxismo un modelo de opus perpetuum en el tercero de los sentidos distinguidos por Losano, el que alude al carácter intrínsecamente unitario de una obra editorialmente dispersa.

\section{2}

\section{Críticas teóricas y actitudes ideológicas}

«Es importante para mí afirmar con toda energía -escribe Kelsen en el prefacio a la 2. ${ }^{a}$ edición de Socialismo y Estado- que mi escrito no se dirige contra el socialismo. Yo sólo me enfrento críticamente con el marxismo y, dentro de él, sólo con su teoría política» ${ }^{7}$; análogamente, en el prólogo a la traducción castellana de La teoría comunista del Derecho y La teoría política del bolchevismo, leemos: «Mis estudios [...] intentan una crítica científica, es decir, objetiva, que no involucra ningún juicio de valor moral o político en favor o en contra del sistema social comunista [...]. Es lógico que toda crítica presuponga un valor; pero el valor presupuesto por una crítica científica no es un valor moral o político, sino lógico; el valor de verdad, no de justicia» ${ }^{8}$. Los escritos kelsenianos de crítica del marxismo no se orientan, en efecto, en el sentido de una crítica ideológico-valorativa: no discuten el valor político o moral del proyecto socialista, sino el mérito científico de las teorías políticas y jurídicas marxistas: sus presupuestos filosófi-

5 F. Riccobono: Introduzione a La teoria generale del Diritto e il materialismo storico, cit., p. 1.

6 Riccobono ha subrayado que La teoría general del Derecho y el materialismo histórico «es obra de notable importancia para la comprensión de los fundamentos teóricos de la Reine Rechtslehre de 1934» advirtiendo que en la primera de estas obras «se anticipan páginas enteras de la Reine Rechtslehre con idéntico contenido conceptual e idéntica forma literaria» (Op. cit., p. 1).

7 Socialismo y Estado (en adelante, S y E, p. 177).

8 Teoría comunista del Derecho y del Estado (en adelante, TcDE), pp. 9-10. 
cos, su consistencia interna y rigor conceptual, su potencia explicativa en la esfera del Derecho y del Estado, su capacidad para trazar cursos de acción no incompatibles con el conocimiento objetivo.

Ello no impide, sin embargo, que estas obras nos suministren también -si bien nunca de manera central- ciertas indicaciones de interés sobre las actitudes de Kelsen, sobres sus simpatías y antipatías ideológico-políticas. $\mathrm{Y}$, en este terreno, debe anotarse tanto la continuidad de ciertas actitudes básicas como determinadas inflexiones entre las obras de los años 20/30 y las posteriores.

2.1. Hay continuidad entre ambos períodos en la simpatía por un socialismo no marxista, reformista en su comportamiento político y que considere al Estado como instrumento no eliminable de la transformación social; hay continuidad también en la oposición al socialismo de inspiración marxista, partidario de una acción política revolucionaria y extincionista en su concepción de las finalidades últimas de esta acción. El laborismo británico permanece, en este sentido, como punto de referencia constante para Kelsen. Así, el escrito de 1924 Marx o Lassalle. Cambios en la teoría política del marxismo acaba con citas del líder laborista MacDonald, acompañadas de expresiones de aprobación por parte de Kelsen, quien considera «la posición de primera línea del socialismo inglés» reflejada en los textos de MacDonald como uno de los elementos que con más firmeza permiten augurar el abandono de la teoría política marxista -que «se ha mostrado insostenible»- por parte del movimiento socialista y su reemplazo por una nueva concepción «no hostil al Estado» que Kelsen auspicia condensándola en la fórmula del regreso a Lassalle ${ }^{9}$. En 1948, en la introducción a La teoría política del bolchevismo aparece de nuevo la alusión al laborismo británico como contrafigura, ahora, del modelo soviético. Admitiendo que de la opción por una u otra vía «dependerá quizá la suerte de la humanidad» escribe Kelsen: «La tentativa rusa de establecer el socialismo mediante la revolución y la dictadura del partido comunista ha encontrado un rival en el empeño del pueblo inglés por alcanzar la misma meta por el camino de la evolución y bajo una verdadera democracia en el sentido tradicional del vocablo» 10 .

2.2. Esta continuidad de actitudes básicas coexiste con elementos diferenciadores entre uno y otro período, que residen, en mi opinión, fundamentalmente en tres puntos: (1) en la implicación personal mostrada por Kelsen en relación con el socialismo; (2) en el tratamiento del sistema político soviético; (3) en la posición adoptada respecto a la posibilidad de integración de su propia construcción teórico-jurídica en la concepción materialista de la historia.

2.2.1. En los textos del primer período cabe espigar diversos pasajes en los que es perceptible una actitud de compromiso personal por parte de Kelsen con el proyecto socialista y con el destino político del movimiento obrero. Así, por ejemplo, en Socialismo y Estado, aludiendo a la implantación

$10 T c D E$, p. 272. 
de «un ordenamiento económico comunista» escribe que ésta es «una experiencia a la que no se debe renunciar a causa de la posibilidad que existe en ella de un mejoramiento de las condiciones insoportables del capitalismo» ${ }^{11}$. En Esencia y valor de la democracia, teniendo como punto de mira no tanto la «catástrofe administrativa» de la Rusia soviética, como los sucesos de Alemania y Austria, manifiesta que «es un hecho dramático que el Gobierno, allí donde ha sido arrebatado por el proletariado, cayese en manos inexpertas, que por ello no fueron capaces de retenerlo» ${ }^{12}$. Finalmente, en Marx o Lassalle parece presentar su propia crítica científica de la teoría política marxista como orientada a esclarecer a la clase obrera respecto a la utilización de la maquinaria estatal. Escribe así: «La suerte de esa clase [la clase obrera], que ahora debe y -a pesar de todas las doctrinas- puede utilizar la maquinaria estatal sin extraviar el camino con la destrucción revolucionaria por amor a una doctrina que ya cumplió su objetivo de agitación y de la que por lo mismo debe olvidarse cuando ascienda, depende del hecho de que el aparato estatal llegue intacto a sus manos. Este es el momento en que la teoría política del marxismo debe derrumbarse» ${ }^{13}$.

Sería vano buscar en los trabajos kelsenianos de los años $40 / 50$ pasajes análogos -en cuanto a la toma de partido por el movimiento obrero expresada en ellos- a los aquí citados.

2.2.2. También en el análisis del poder soviético hay un camino de acentos notable entre ambos períodos de la crítica kelseniana. En los textos de los años 20 Kelsen dirige al sistema político soviético críticas importantes, de las que probablemente las más significativas sean las siguientes: primero, la constitución soviética, lejos de realizar el principio de universalidad de los derechos políticos, priva de los mismos a algunos sectores de la población (la «burguesía») y los atribuye de manera desigualitaria al resto (sobrerepresentación del proletariado industrial frente al campesinado): de acuerdo con ello, la constitución soviética no es una constitución democrática, sino precisamente «la negación de la democracia»: en tanto que garantiza situaciones de privilegio político se trata de una constitución a la que cuadra con propiedad el calificativo de «aristocrática» ${ }^{14}$; segundo, es incompatible con los valores democráticos la justificación ideológica de este privilegio político del proletariado, basada en la consideración de que «el proletariado no representa una clase limitada, sino más bien toda la sociedad, por lo menos la sociedad del futuro»; pues esta atribución de universalidad a los intereses proletarios «es la absolutización dogmática del ideal político de una determinada visión de la sociedad; es la ficción típica de todo régimen aris-

\section{$11 S$ y $E$, p.302}

12 Esencia y valor de la democracia, trad. de Rafael Luengo Tapia y Luis Legaz Lacambra de la 2. ${ }^{a}$ ed. (1929) de Vom Wesen und Wert der Demokratie, Labor, Barcelona, 1977, p. 125. El volumen incluye un prólogo de Ignacio de Otto y el trabajo de Peter Romer La teoría pura del Derecho, de Hans Kelsen, como ideología y como crítica de la ideología.

13 En $S$ y E, p 375.

$14 S$ y E, pp. 338 y 346. 
tocrático y autocrático; es, ante todo, la ideología de la teocracia» ${ }^{15}$; tercero, los ideólogos soviéticos -muy especialmente Lenin- han desplazado el significado del término 'democracia', que ha dejado de indicar un determinado método para la creación del orden social para pasar a hacer referencia al contenido de ese mismo orden; este desplazamiento cumple la función -dando lugar, así, a lo que hoy llamaríamos una definición persuasivade utilizar «la gran autoridad y el crédito de que el lema de la democracia goza» en favor de «un sistema expresamente dictatorial» 16 .

Estas críticas -sobre algunas de las cuales volveremos más adelantevan, sin embargo, acompañadas del señalamiento de aspectos positivos, entre ellos el propio sistema piramidal de soviets y la posibilidad permanente de revocación de los representantes que este sistema contempla. Escribe, en este sentido: «cuando se señala el hecho de que la elección indirecta por parte de las personas reunidas diariamente en las empresas es más adecuada para expresar las intuiciones de las masas que cambian rápidamente en la revolución, que el pesado aparato de las elecciones universales y directas, que sólo se ponen en movimiento en intervalos de tiempo más largos, esto es ciertamente exacto» ${ }^{17} ; \mathrm{y}$, refiriéndose a la «posibilidad -que existe evidentemente en relación con los miembros de todos los soviets- de una revocación en cualquier momento, sobre la base de una evaluación libre» señala que «en este punto precisamente la constitución conciliar soviética realiza un principio absolutamente democrático. Y supera las degeneraciones de la democracia que en el sistema representativo surgieron (...)» ${ }^{18}$. También valora Kelsen muy positivamente la equiparación de derechos políticos entre nacionales y extranjeros residentes en el territorio por razón de trabajo llevada a cabo por la constitución soviética: esta equiparación constituye, en su opinión, «un acto de importancia histórico-universal y un fuerte paso hacia la realización del concepto -absolutamente democrático- de humanidad» ${ }^{19}$.

En la obra de 1948 en que vuelve sobre el tema -La teoría política del bolchevismo- ya no hay mención alguna de eventuales aspectos positivos. Y, lo que tiene quizás más interés, asistimos en ella a un curioso giro iusrealista difícilmente ajustable a los postulados metódicos kelsenianos, mediante el que se distingue, para dar cuenta del sistema de poder soviético, el law in books del law in action ${ }^{20}$. La constitución stalinista de 1936 -que eli-

15 S y E, pp. 347-348.

16 Esencia y valor de la democracia, pp. 127-128.

$17 S$ y E, p. 337. Cfr., en el mismo sentido, Esencia y valor de la democracia, p. 61.

$18 S$ y $E$, p. 340.

$19 S$ y E., p. 328. En el mismo sentido, Esencia y valor de la democracia, p. 34.

20 Sobre este sorprendente giro iusrealista de Kelsen ha llamado también la atención R. Guastini: La dottrina pura del diritto e il marxismo, en Id.: Lezioni di teoria analitica del diritto Giappicheli, Torino, 1982, pp. 182 y ss. (Una versión algo más breve de este trabajo de Guastini, con el título de Kelsen crítico del marxismo, se encuentra en el volumen Hans Kelsen nella cultura filosofico-giuridica del Novecento, ed. de Carlo Roehrsen, Istituto della Enciclopedia Italiana, Roma, 1983, pp. 135 y ss.). 
minaba las anteriores discriminaciones clasistas respecto al derecho de sufragio ${ }^{21}$ - es estudiada en dos apartados de este trabajo. En el primero de ellos (La Constitución de 1936), Kelsen, de manera plenamente conforme a su concepción de la labor del jurista teórico, atiende al contenido ideal de las normas constitucionales, desprendiéndose de su análisis que «la constitución soviética satisface todos los requisitos de una democracia avanzada, salvo uno: no hay libertad para la formación y la actividad de partidos políticos» ${ }^{22}$. Sin embargo, en el apartado siguiente (La realidad política en la Rusia soviética) -que empieza significativamente con los términos «en la realidad [... ]»- Kelsen contrapone al sistema de normas constitucionales válidas la descripción del funcionamiento efectivo del sistema político, para concluir que «la constitución soviética de 1936 es una espléndida fachada democrática detrás de la cual un grupo relativamente reducido de hombres ejercen un control sin restricciones sobre una de las naciones más grandes del mundo» 23 .

2.2.3. Un contraste aún más evidente presentan ambos períodos de la crítica kelseniana por lo que hace a la posiciónadoptada en uno y otro frente a la posibilidad de integración de la teoría pura del Derecho en la concepción materialista de la historia. En La teoría general del Derecho y el materialismo histórico (1931) señala Kelsen que «la tarea propia de la concepción materialista de la historia respecto a la teoría general del Derecho no puede consistir más que en tratar de mostrar la teoría general del Derecho -tal como se presenta en las obras de los juristas burgueses y se enseña en las Facultades estatales- como una ideología, o, al menos, en poner de manifiesto la función ideológica de los conceptos y de las tesis producidos por ella» ${ }^{24}$. Pues bien, más que los autores marxistas (prisioneros, ellos también, de los dualismos ideológicos de la teoría del Derecho tradicional) es la teoría pura del Derecho (que, obedeciendo exclusivamente a móviles científicos, no hace suyo el fin político que la concepción materialista de la historia considera propio, ni ningún otro) quien está realizando «desde hace dos decenios», este programa antiideológico correspondiente a la concepción materialista de la historia, llevando a cabo «una enérgica lucha contra la mayor parte de las posiciones de la teoría jurídica tradicional, y precisamente con arreglo al método de una crítica de la ideología. En este punto -concluye Kelsen- los resultados de esta tendencia de la más reciente ciencia jurídica coinciden en amplísima medida con las tendencias de la concepción materialista de la historia y redundan en su favor» ${ }^{25}$.

21 Sobre la Constitución soviética de 1936, cfr. Manuel García Álvarez: Textos constitucionales socialistas, Colegio Universitario de León, 1977, pp. 41-56. La valoración oficial de la misma puede verse en la Historia del partido comunista de la URSS redactada en 1938 por una comisión del comité central bajo la inspiración de Stalin (cito por la trad. francesa: Histoire du parti communiste (bolchévik) de l'URSS, Éditions Gitle-Coeur, Paris, s. f., pp. 322-326).

$22 T c D E$, p. 336.

23 Id., pp. 338-9.

24 La teoria generale del diritto e il materialismo storico (en adelante TGD e m.s.), p. 55.

25 Id., p. 56. 
Por el contrario, en La teoría comunista del Derecho (1955), el acento se desplaza hacia la consideración del marxismo como incompatible en su raíz con una teoría aideológica del Derecho: así, tras señalar el «carácter abiertamente ideológico» de la teoría jurídica soviética «determinada esencialmente por los intereses políticos del gobierno soviético», advierte Kelsen que este «carácter ideológico de la teoría soviética del Derecho es consecuencia inevitable del principio marxista -contrario al postulado antiideológico- de que la ciencia social en general y la ciencia del Estado y del Derecho en particular tienen que ser políticas, es decir, tienen que traducirse en fórmulas que puedan ser usadas en la lucha política de un grupo contra otro» ${ }^{26}$.

2.3. Estos desplazamientos en la actitud de Kelsen frente al socialismo y al marxismo tienen, sin duda, interés como elementos de la entera biografía espiritual (es decir, no meramente teórico-jurídica) kelseniana. Y, en este sentido, nos muestran a un Kelsen cuya evolución viene a coincidir con la de tantos intelectuales liberales (en el mejor sentido de la expresión) que de un interés positivo -si bien, al menos en el caso de Kelsen, siempre crítico- hacia el marxismo y hacia las experiencias socialistas pasaron después -tras la identificación del marxismo con la ideología del régimen vigente en la URSS y tras la evolución de este mismo régimen- a adoptar actitudes de clara hostilidad ${ }^{27}$.

Ello no obstante, la importancia de estos cambios en las actitudes kelsenianas no debe ser exagerada. Y ello no tanto porque todas las cuestiones de actitud se encuentren, en opinión de Kelsen, situadas fuera del universo de la razón, sino, sobre todo, por la más decisiva circunstancia de que como ya se ha indicado- las críticas teóricas de Kelsen al marxismo perma-

\section{TcDE, pp. 266-267.}

27 Francamente exagerada me parece la observación incidentalmente formulada por Mario G. Losano, a tenor de la cual La teoría comunista del Derecho de 1955 fue «un peaje pagado al maccarthismo» (Mario G. Losano: La dottrina pura del diritto e la psicoanalisi, en Id.: Forma e realtà in Kelsen, Comunità, Milano, 1981, p. 138). Conviene advertir en todo caso -para percibir adecuadamente los límites de la evolución ideológica kelseniana en relación con otros intelectuales adscribibles a análoga atmósfera cultural- que Kelsen jamás llegó a las conclusiones de un Popper, quien, en su Unended Quest, escribe que «una cosa tal como el socialismo combinado con la libertad individual [...] no es más que un bello sueño [...]; el intento de realizar la igualdad pone en peligro la libertad» (K. R. Popper: Búsqueda sin término. Una autobiografía intelectual, trad. de Carmen García Trevijano, Tecnos, Madrid, 1977, p. 49). Kelsen, bien al contrario, y precisamente el mismo año en que publica The Communist Theory of Law, escribe en The Foundations of the Democracy que «ni el capitalismo ni el socialismo se encuentran conectados por su naturaleza con un determinado sistema político. Cada uno de ellos puede instituirse tanto bajo un régimen democrático como bajo un régimen autocrático»; en explícita polémica contra la afirmación de F. A. Hayek de que la economía planificada requiere la supresión de la libertad indica que, en este orden de cosas «el experimento ruso, limitado a una gran potencia y algunos pequeños satélites, y al lapso de una sola generación, no prueba nada»; y, finalmente, aludiendo a «los ideólogos del socialismo no marxista [que sostienen que] la democracia debe combinarse con el socialismo» comenta: «personalmente no soy contrario a este programa político y creo que la democracia es compatible con el socialismo» (cito por la trad. italiana: I fondamenti della democrazia, en H. Kelsen: La democrazia, Il Mulino, Bo-

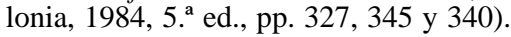


necen constantes, de uno a otro período, sin verse afectadas por estas inflexiones en las actitudes de su autor. Ésta permanencia de sus posiciones y críticas teóricas frente a sus propios cambios de actitud permite exponer unitariamente las primeras y -lo que es más importante- constituye sin duda un argumento no desdeñable, que quizá fuera del agrado del propio Kelsen, en favor del carácter aideológico de las mismas.

\section{3}

\section{Predicción y programa en el marxismo}

«Para nosotros, -escriben Marx y Engels en La ideología alemanael comunismo no es un estado que deba implantarse, un ideal al que haya de sujetarse la realidad. Nosotros llamamos comunismo al movimiento real que anula y supera al estado de cosas actual» ${ }^{28}$.

Para Kelsen, la concepción expresada en este texto -en el que la idealidad no se reconoce como tal, escondiéndose bajo la apariencia de una descripción moralmente neutra- refleja «la confusión más radical de los límites entre realidad y valor» ${ }^{29}$ al presentar «postulados ético-políticos revolucionarios como leyes de desarrollo que se realizan por una necesidad natural» ${ }^{30}$. La ignorancia -que el marxismo hereda de Hegel- de la gran división entre ser y deber ser tiene, en opinión de Kelsen, consecuencias devastadoras para esta doctrina, tanto si es contemplada desde el punto de vista normativo como si se atiende a su pretensión de constituir una teoría explicativo-predicativa del desarrollo de la sociedad.

3.1. Desde un prisma normativo, el marxismo resulta insostenible porque, dada la irreductibilidad de los valores a los hechos, «jamás de los jamases se puede dar una respuesta al justo fin de la acción a través del conocimiento de lo que acontece y tal vez, verosímilmente, habrá de acontecer»; de forma que «es indiferente -para el valor y precisión de un fin- que su realización se presente como inevitable». Y Y así «ni siquiera la comprobación de las tendencias más fuertes del desarrollo hacia un orden socialista de la sociedad [...] es capaz de justificar el socialismo como programa político, como fin del querer y del actuar» ${ }^{31}$. El intento de fundamentación del fin orientador de la acción en su pretendida inevitabilidad futura configura, pues, al marxismo como una especie más de naturalismo ético (de tipo historicista).

28 K. Marx-F. Engels: La ideología alemana, Ed. Pueblos Unidos, Montevideo, 1968, p. 37. La ideología alemana permaneció inédita, como se sabe, hasta 1932. No pudo ser tomada en cuenta, pues, por Kelsen en sus primeras obras de crítica del marxismo, aunque sí es varias veces citada en La teoría comunista del Derecho. He escogido, en todo caso, este pasaje -de entre otros muchos del mismo género que pueden encontrarse en Marx- por expresar muy diáfanamente aquello que constituye el objeto de la crítica kelseniana.

29 S. y E., p. 179.

30 Id., p. 184.

31 Id., p. 180. 
3.2. La autopresentación del marxismo como teoría científica, explicativo-predictiva, del acontecer social no queda mejor parada: pues la profecía del comunismo no es prognosis científica, sino -al igual que las «tendencias naturales» de los iusnaturalistas- fruto de una valoración no declarada introducida en el examen del desarrollo social: «así como la doctrina del Derecho natural -escribe- puede deducir de la naturaleza sólo lo que ha proyectado previamente en ella [...] la verdad social que Marx pretende hacer surgir de la realidad social es su propia ideología socialista, proyectada sobre aquélla» ${ }^{32}$; «este descubrimiento científico [el comunismo como término al que se dirige la evolución social] es posible sólo porque el valor pretendidamente descubierto ha sido previamente proyectado a la realidad» ${ }^{33}$. El marxismo no es, pues, una teoría científica, sino más bien una filosofía teleológica de la historia ${ }^{34}$.

\section{4}

\section{La dialéctica}

La dialéctica constituye otro de los blancos de la argumentación kelseniana contra los presupuestos filosóficos del marxismo. Las críticas afectan, a este respecto, (1) a la identificación entre oposiciones reales y contradicciones lógicas y (2) al carácter valorativo de la concepción dialéctica del cambio.

4.1. La filosofía dialéctica que el marxismo hereda de Hegel identifica, en opinión de Kelsen, oposiciones reales y contradicciones lógicas: ello hace a las teorías marxistas no susceptibles de control racional dado que, sobre

32 La teoría comunista del Derecho (TcDE, p. 42).

33 Id. (TcDE, p. 72).

34 Es probablemente en estos puntos -consideración del marxismo como naturalismo (historicista) ético; carácter no científico de la predicción del comunismo- donde las críticas de Kelsen y de Popper al marxismo presentan una mayor proximidad. La reconstrucción de la metaética de Marx y la crítica a la misma son substancialmente coincidentes en ambos autores (Cfr. La sociedad abierta y sus enemigos (1945), trad. cast. de Eduardo Laedel, Paidós Ibérica, Barcelona, 1981, pp. 370-380) si bien Popper muestra, por así decirlo, una comprensión empática de las motivaciones que llevaron a Marx a adoptar una concepción tal de la ética -y que puede resumirse en la frase: «Marx evitó formular una teoría moral explícita porque aborrecía los sermones» (op. cit., p. 370)- que está por completo ausente de los escritos kelsenianos. Asimismo, hallamos en Popper una apreciación muy positiva de lo que llama el «radicalismo moral» de Marx -al que sitúa más allá de su autoconsciencia explícita en este terreno- que tampoco es posible encontrar en Kelsen.

Respecto a la no cientificidad de la predicción del comunismo, también Popper señala la presencia en ella de «un alto grado de pensamiento emocional» (La sociedad abierta y sus enemigos, trad, cast. cit., p. 368); sin embargo, la razón principal del rechazo de las pretensiones de la misma de constituir una predicación científica, y de su consideración como profecía, es para Popper, como se sabe, su carácter incondicionado y, por ello, irrefutable (Cfr. La miseria del historicismo, (1944-45), trad. cast. de Pedro Schwartz, Alianza, Madrid, 1973, esp. p. 143 y Predicción y profecía en las ciencias sociales (1948), en Conjeturas y refutaciones, trad. cast. de Néstor Miguez y Rafael Grasa, Paidós Ibérica, Barcelona, 1983, pp. 403 y ss.). 
la base de dicha identificación, los marxistas consideran que poner de relieve la presencia de proposiciones contradictorias en el interior de una teoría no constituye una objeción a la misma. Ya en La teoría general del Derecho y el materialismo histórico encontramos advertencias en este sentido: a propósito de ciertas consideraciones de Pasukanis sobre las contradicciones de la teoría burguesa del Derecho como fiel reflejo de las contradicciones del Derecho burgués, escribe Kelsen: «Toda esta argumentación de una dialéctica que se pierde en místicas tinieblas vive de un equívoco inadmisible. Llamando a una real oposición de intereses «contradicción», no se adquiere el derecho de identificarla con una contradicción lógica. Se puede representar una oposición real de intereses igual que la relación de dos fuerzas físicas que actúan en dirección opuesta sin ninguna contradicción lógica. Esto nunca será puesto de relieve con suficiente energía contra todo intento dialéctico de oscurecimiento [...]. La identificación de oposición real y contradicción lógica sólo puede enredar en contradicciones insoportables incluso una tal concepción dialéctica de la historia» ${ }^{35}$. Es sin embargo, en La teoría política del bolchevismo y en La teoría comunista del Derecho donde la crítica kelseniana se explicita más y se dirige, no ya contra un determinado jurista marxista, sino contra el marxismo como tal: en la primera de ellas señala Kelsen que «Marx, lo mismo que Hegel, interpreta los conflictos de la lucha por la vida, el antagonismo entre grupos de intereses opuestos, y en especial el desacuerdo de fuerzas productivas y modo de producción, como contradicciones lógicas [...]; pero en contraposición a Hegel, y con menos coherencia que éste, no identifica pensamiento y ser» ${ }^{36}$. En La teoría comunista del Derecho caracteriza al marxismo como «una teoría que -bajo la guía de la lógica dialéctica de Hegel- transfiere las contradicciones lógicas del pensamiento al ser» ${ }^{37}$. Ello explica por qué «el que una teoría se enrede en contradicciones lógicas no constituye objección desde el punto de vista de la nueva lógica, la lógica dinámica de la dialéctica, que Marx y Engels tomaron de la filosofía de la historia de Hegel [...]. Si las contradicciones lógicas son inherentes a la realidad las contradicciones en el pensar no son un defecto lógico [...]. Marx y Engels hicieron abundante uso de la nueva lógica dialéctica $\left[\ldots . . .{ }^{38}\right.$.

4.2. La concepción dialéctica del cambio (social, por lo que nos interesa) implica, en opinión de Kelsen, considerar que el valor es un atributo de la realidad (social) presente o futura (se trata, como puede verse, de la misma crítica recogida en el $\S 3$, formulada ahora a propósito de la dialéctica). Ello le permite «presentar lo que es simplemente un postulado político basado en juicios subjetivos de valor, como el resultado necesario de una evolución, determinada por leyes objetivas, que conduce necesariamente de un nivel inferior de cultura a otro más elevado. Si la realidad no corresponde al valor postulado, presuntamente inherente a aquélla, se transfiere al futu-

\footnotetext{
35 T.G.D. e.m.s., pp. 152-153.

36 T.c.D.E., p. 291.

37 T.c.D.E. p. 39.

38 T.c.D.E., pp. 78-79.
} 
ro al inexorable realización de ese valor» ${ }^{39}$. Esta arbitrariedad en la atribución del valor, bien a la sociedad presente, bien a la futura, explica -junto con «su carácter totalmente optimista, su tesis de que la realización progresiva de un estado ideal de la humanidad es el resultado necesario del proceso histórico» 40 - la funcionalidad y adaptabilidad de la dialéctica a las exigencias de cualquier ideología política, tanto de signo conservador (Hegel) como revolucionario (marxistas): pues «cualquier situación histórica puede ser interpretada de modo que represente la tesis, o la antítesis, o la síntesis, de acuerdo con la evaluación política que de ella haga el intérprete» ${ }^{41}$.

\section{El concepto de «Estado»}

Una primera crítica de Kelsen a la teoría política del marxismo afecta a la definición de «Estado». En Marx y los marxistas, usualmente encontramos definiciones de «Estado» de tipo funcional: el Estado aparece definido en ellas -bajo una $\mathrm{u}$ otra formulación- como maquinaria dirigida al mantenimiento de la explotación de clase. Kelsen acepta que bajo esta definición funcional se halla algo que empíricamente es probablemente verdadero, aunque parcial, a saber, que el Estado bajo el capitalismo cumple efectivamente, entre otras, esta función de garantía de la explotación: «El Estado moderno -escribe- puede considerarse seguramente como un medio para el objetivo de la explotación económica de una clase por parte de otra» ${ }^{42}$ si bien no es menos cierto, en su opinión, que ese mismo Estado «es apto para actuar en la dirección de la supresión de clases» como lo muestra «la legislación de política social [que] ha sido puesto en práctica por la presión cada vez mayor de las organizaciones de los trabajadores» ${ }^{43}$. Acepta también Kelsen -en este punto dice «estar de acuerdo plenamente con la teoría marxista»- el carácter ideológico de toda concepción del Estado como expresión de un presunto interés común: concepciones de este género constituyen una «ficción» que «consciente o inconscientemente persigue la finalidad de

39 La teoría política del bolchevismo (T.c.D.E., p. 292).

40 Id. (T.c.D.E., pp. 287-288).

41 Id. (T.c.D.E., p. 292). También en las críticas a la dialéctica hay una coincidencia notable entre Kelsen y Popper. En Popper se encuentra, sin embargo, una razón más en contra del principio dialéctico de admisibilidad de proposiciones contradictorias: se trata de la demostración de que «si se admiten dos enunciados contradictorios, entonces se debe admitir cualquier enunciado; pues de un par de enunciados contradictorios puede inferirse válidamente cualquier enunciado», de modo que «si una teoría contiene una contradicción, entonces implica todo y, por lo tanto, nada» (Qué es la dialéctica (1937) en Conjeturas y refutaciones, cit., pp. 375 y ss.: 381 y 383). Con todo, Popper parece tomarse menos en serio que Kelsen tanto la dialéctica como tal como el papel de la misma en el marxismo: las tesis de la dialéctica no habría tanto que tomarlas en su literalidad -como hace Kelsen- sino más bien como manifestaciones de una manera «vaga» y «metafórica» de hablar. Sobre esto se volverá más adelante.

42 S y E. p. 189.

43 Id., p. 190. 
mantener obedientes a aquellos contra cuyos intereses existe en cada caso el ordenamiento estatal constrictivo» ${ }^{44}$.

En el desacuerdo de Kelsen con el marxismo en punto al Estado hay, desde luego, una vertiente de tipo empírico, terreno en el que Kelsen discrepa -como se acaba de ver- de la tesis según la cual el Estado bajo el capitalismo sólo opera y sólo puede operar como instrumento de la explotación. Pero, más allá de este desacuerdo empírico, la principal divergencia entre Kelsen y el marxismo es de naturaleza propiamente conceptual. Pues lo que Kelsen impugna es que sea científicamente pertinente una definición funcional de «Estado» (o de «Derecho»: recuérdese que ambos términos denotan, en la teoría pura, el mismo objeto). En una definición de este tipo se pierde de vista precisamente lo específicamente jurídico-estatal, que no es una determinada función o contenido (que puede compartir con otros sistemas normativos no jurídicos: morales, religiosos...) sino precisamente una forma -esto es, el constituir un «sistema de normas que ordenan la constricción» ${ }^{45}$ - que, en cuanto tal, puede servir para realizar cualquier función social o, lo que es lo mismo, puede llenarse de cualquier contenido: «el dominio llamado "Estado" u "ordenamiento jurídico", el llamado «aparato constrictivo» se caracteriza por constituir -escribe Kelsen- «una forma específica de la vida social, que puede asumir contenidos muy variables, un medio de técnica social, con el que se pueden perseguir los objetivos más diversos» ${ }^{46}$. Además, una razón adicional para rechazar la definición funcional de «Estado» que el marxismo propone se halla en el hecho -y aquí la crítica de Kelsen es plenamente interna- de que, si se parte de dicha definición, una tesis importante del marxismo (la tesis de la dictadura del proletariado, del Estado de los proletarios) resulta inconsistente con ella, en tanto que su tesis programática final (la extinción del Estado) queda reducida a una mera tautología. En efecto, si se define el Estado como maquinaria coercitiva para la explotación de una clase por otra ¿cómo se cohonesta esta definición con la postulación de un Estado proletario para la fase de transición cuya función histórica haya de ser «la abolición definitiva de toda explotación de una clase por otra» ${ }^{47}$. Y en cuanto a la extinción del Estado, «si por "Estado" sólo se entendiera la opresión de clase basada en la explotación [...] la famosa teoría de la "extinción del Estado" debería ir a parar en la afirmación de que, cuando desaparezca la opresión de clase basada en la explotación se extinguirá también la opresión de clase basada en la explotación» ${ }^{48}$. Por todo ello concluye Kelsen que, tanto en el contexto de la «dictadura del proletariado» como en el de la «extinción del Estado», el concepto de «Estado» implícitamente usado por los marxistas es el de «orden coercitivo centralizado» es decir, «exactamente [aquel que] los marxistas tra-

\footnotetext{
44 Id., p. 194-195.

45 Id., p. 188.

46 Id., p. 189.
}

47 La teoría política del bolchevismo (T.c.D.E., p. 296).

48 S y E., p. 192. 
tan de ridiculizar como "formalista", porque no incluye el objeto sustancial de esta maquinaria coercitiva, el contenido de este orden coercitivo»" ${ }^{49}$.

\section{6}

\section{La extinción del Estado}

6.1. La crítica a la tesis de la extinción del Estado constituye otro de los puntos nodales de la crítica kelseniana al marxismo como teoría política. Antes de ocuparnos directamente de ella es conveniente, sin embargo, prestar alguna atención a la reconstrucción filológica que Kelsen hace del lugar y de la importancia de la tesis extincionista en el conjunto de la doctrina marxista. En este sentido, no puede dejar de observarse en el análisis kelseniano de los textos marxistas sobre el tema la existencia de un salto interpretativo para el que no se aduce justificación. Se trata de lo siguiente: cuando Kelsen examina la tesis de la extinción del Estado en Marx, su lenguaje es cauteloso a la hora de atribuírsela sin fisuras y se esfuerza en poner de relieve las oscilaciones que, en este punto, cabe encontrar en los textos de Marx; por el contrario, cuando su atención se dirige a los marxistas de la segunda generación o cuando alude al marxismo sin más, Kelsen presenta la extinción del Estado como el punto programático esencial de esta doctrina. Veámoslo:

6.1.1. Señala Kelsen que «se encuentran en Marx pasajes en los que éste se opone, de la manera más decidida, no simplemente al Estado de clase capitalista, sino al Estado en general» ${ }^{50}$. Ejemplos particularmente característicos de esta presencia del «ideal anárquico» en Marx se encuentran a juicio de Kelsen, en los análisis sobre la Comuna de París contenidos en $L a$ guerra civil en Francia ${ }^{51}$. Hay sin embargo -observa asimismo Kelsenotros textos de Marx en los que su adhesión a las tesis extincionistas es mucho menos clara. Tal es el caso de la Crítica del programa de Gotha en el que Marx, a propósito de la pregunta «¿qué transformaciones sufrirá el Estado en la sociedad comunista?» se abstiene de toda respuesta categórica para limitarse a apuntar que «esa pregunta sólo puede contestarse científicamente» ${ }^{52}$. Comentando este pasaje, escribe Kelsen: «Marx, sin embargo, no dio esa respuesta "científica" ${ }^{53}$. Y, por lo que hace al pasaje sobre la «superación del estrecho horizonte del Derecho burgués» en el comunismo (perteneciente asimismo a la Crítica del programa de Gotha), Kelsen hace ver que este dictum puede interpretarse tanto en el sentido de aludir a la superación del principio fundamental del Derecho burgués (retribución según el trabajo) en otro ordenamiento jurídico que realice el principio de retribución según las necesidades, como en el de entender que Marx pretendía referirse a la superación de toda forma de ordenamiento jurídico ${ }^{54}$. Del análisis de

49 La teoría política del bolchevismo (T.c.D.E., p. 296).

$50 S$ y E, p. 247.

51 Cfr. S. y E., pp. 240 y ss.

52 K. Marx: Crítica del programa de Gotha (citado por Kelsen en S. y E., p. 258).

53 S y E, p. 259.

54 Id., pp. 200-261. 
los textos marxianos efectuado por Kelsen se deduce, pues, que no es posible dar una respuesta inequívoca a la pregunta de si el objetivo extincionista forma o no parte plenamente integrante del pensamiento político de Marx.

6.1.2. Es por ello sorprendente que el mismo Kelsen escriba poco después que «Lenin repitió correctamente los puntos de vista de Marx y Engels acerca de la última frase suprema del desarrollo socialista» ${ }^{55}$, que «la teoría política tal y como la desarrollaron Marx y Engels es anarquismo puro» ${ }^{56}$ y que, por ello, «el mérito indiscutible de los trabajos de Lenin y de los demás autores bolcheviques consiste en haber restablecido la verdadera teoría del Estado de Marx y Engels» ${ }^{57}$. Calificada así la interpretación leninista como la única fiel a Marx, Kelsen reprochará a los marxistas defensores de la necesidad de un orden constrictivo también en la fase superior del socialismo (Kautsky, Renner, Bauer) no el fondo de sus posiciones con el que obviamente estaba de acuerdo- sino su pretensión de presentarlas como no opuestas a la doctrina de Marx ${ }^{58}$. Ni la tajante atribución de ortodoxia al estincionista Lenin ni la no menos rotunda consideración como no marxistas de las orientaciones estatalistas de Kautsky, Renner o Bauer acaban de compadecerse bien con el propio análisis kelseniano de los textos de Marx.

6.2. Sea como fuere -y abandonando ya el campo de la Marx-philologie kelseniana- la tesis de la extinción del Estado constituye, como decía, uno de los blancos centrales de la crítica de Kelsen. La argumentación al respecto -que se repite prolijamente una y otra vez en sus diversas obras sobre el marxismo- puede reconducirse, en mi opinión, a las dos líneas siguientes: en primer lugar, la extinción del Estado como programa político es inconsistente con el programa económico del marxismo, que propugna la absoluta socialización de la economía y la centralización de las decisiones económicas; en segundo lugar, un orden social sin constricción, esto es, sin Estado, requiere determinadas condiciones factuales cuya realizabilidad no se encuentra en modo alguno fundamentada y es, en todo caso, incompatible con lo que sabemos de la naturaleza humana. Esta segunda línea argumentativa resulta, desde luego, -independientemente de su razonabilidad- chocante en quien, como Kelsen, ha criticado tanto toda forma de iusnaturalismo y ha enfatizado en tan gran medida la inexistencia de puentes entre «es» $\mathrm{y}$ «debe».

6.2.1. La primera de las líneas de crítica kelseniana a la tesis de la extinción del Estado es, como se ha indicado, inmanente al propio marxismo. Pues el programa económico de éste encuentra su culminación, en efecto,

55 Id., p. 292.

56 Marx o Lassalle (S y E, p. 368).

57 Id. (S y E, pp. 368-369).

58 Cfr. $S$ y E, pp. 279-290 y Marx o Lassalle (S y E, pp. 375-394). Tan sólo escapa a este reproche $\mathrm{H}$. Cunow, «uno de los mejores teóricos del marxismo», en opinión de Kelsen, pues este autor -en su libro Die Marxsche Geschichts -Gessellschafts- und Staatstheorie, Berlín, 1920 -presenta su propia posición estatalista como conscientemente ajena a la de Marx y Engels (cfr. Marx o Lassalle -S y E, pp. 394 y ss-). 
en una «organización de la economía rígida, colectivista-centralizada», mientras que su «doctrina política aspira evidentemente a un ideal anarquistaindividualista» ${ }^{59}$. Hay, por ello, una «contradicción, en el sistema del socialismo "científico", entre la situación legal de la sociedad comunista del futuro, que se presume será de anarquía individualista, y la situación económica, que consistirá en el reemplazo de la "anarquía de la producción capitalista" por una producción altamente organizada sobre la base de la propiedad colectiva de los medios de producción, concentrada necesariamente en manos de una autoridad central» ${ }^{60}$. El que esta contradicción haya podido pasar desapercibida se ha debido en gran medida -observa Kelsena la «apariencia seductora» de la fórmula engelsiana según la cual en la sociedad comunista «el gobierno de las personas es sustituido por la administración de las cosas, por la dirección de los procesos productivos» ${ }^{61}$. Pero la magia de esta fórmula se disipa en cuanto advertimos que la dicotomía entre dominio político sobre los hombres y administración económica de las cosas, sobre la que la misma se basa, resulta insostenible. Pues «como las cosas son administradas y los procesos de producción son dirigidos por personas, la administración de las cosas y la dirección de los procesos de producción no son posibles sin un gobierno sobre las personas y poca duda cabe de que la centralización de todo el proceso de producción económica requerirá un alto grado de autoridad» ${ }^{2}$.

6.2.2. La inconsistencia, interna al marxismo, de propugnar la extinción del Estado como programa político en tanto que, simultáneamente, se aboga en el plano económico por la colectivización centralizada no constituye, con todo, la razón principal del rechazo kelseniano de la tesis extincionista. Este se fundamenta más bien -y aquí la crítica se hace externa- en la consideración de que dicha perspectiva es irrealizable, por tener como fundamento una predicción no fundamentada de crecimiento económico virtualmente ilimitado y una imagen inadecuada de la naturaleza del hombre como ser social. La admisión de la realizabilidad del comunismo como sociedad anárquica se halla condicionada, en efecto, en primer lugar, a la suposición de que «la socialización de los medios de producción aumentará la producción en tal medida que todas las necesidades económicas podrán ser satisfechas» ${ }_{64}^{63}$. Esta suposición «no halla fundamento en nuestra experiencia social» ${ }^{64}$. Por lo que hace a la fase socialista «es cierto que [la socialización] implica una tendencia al aumento de la producción, pero tam-

\section{S y E, p. 271.}

60 La teoría comunista del Derecho (T.c.D.E., p. 77). Cfr. también The Law as a Specifc Social Technique (1941) (trad. cast.: El Derecho como técnica social específica, en ¿Qué es justicia?, trad. y estudio preliminar de A. Calsamiglia, Barcelona, Ariel, 1982, p. 166).

61 El pasaje pertenece, como se sabe, al Anti-Dühring. Kelsen lo cita en $S$ y E, p. 270 $y$ en La teoría comunista del Derecho (T.c.D.E., p. 78).

62 La teoría comunista del Derecho (T.c.D.E., p. 78); cfr. también $S$ y E, p. 271).

63 La teoría comunista del Derecho (T.c.D.E., p. 64).

62 Id. (T.c.D.E., p. 65). 
bién la tendencia opuesta; y los resultados de la socialización, en cuanto se ha podido observarlos hasta el momento, no confirman la optimista predicción de Marx» ${ }^{65}$. La predicción de «un aumento extraordinario de la producción» es aún menos plausible cuando se refiere a la fase propiamente comunista «ya que según Marx será abolida la división del trabajo, que es uno de los medios más efectivos de elevar la producción, tanto cualitativa como cuantitativamente» ${ }^{66}$. Este carácter no ilimitado de la riqueza disponible originará la persistencia, también en la sociedad comunista, de conflictos distributivos, pues «entre las necesidades que los hombres subjetivamente sienten se producen conflictos tales que impiden que ningún orden social resulte capaz de satisfacer todas esas necesidades, si no es satisfaciendo unas a expensas de otras» ${ }^{67}$. Y, por la misma razón, tampoco puede dejarse al arbitrio individual la determinación de las capacidades que cada uno ha de aportar al producto social, sino que «estas cuestiones deberán necesariamente ser decididas y resueltas por los órganos competentes de la colectividad según las normas de su ordenamiento» ${ }^{68}$. Una eventual sociedad comunista, si bien eliminaría las clases sociales y, con ellas, los antagonismos de clase, no traería pues aparejada -contra lo que piensan los marxistas- la desaparición de todo conflicto económico: aun en una sociedad sin clases surgirán conflictos de esta naturaleza tanto en la esfera de la producción (determinación de las capacidades a aportar) como en la de la distribución (determinación de las necesidades a satisfacer).

Pero aun cuando la sociedad comunista lograra la eliminación de todo conflicto económico -lo que, como acabamos de ver, no es el caso- ello no implicaría la realizabilidad de un orden social sin constricción. Pues no hay, en opinión de Kelsen, ninguna razón para pensar que la ausencia de conflicto económico haya de conllevar la desaparición de las restantes fuentes de enfrentamiento entre los hombres. A este respecto, Kelsen ve en el marxismo una concepción de la naturaleza humana cuyo decidido optimismo no tiene otra base más que lo que podríamos llamar un entendimiento injustificadamente monista de las determinaciones de la conducta social de los hombres: si el marxismo cree posible una sociedad básicamente aconflictual (y, por lo tanto, capaz de prescindir de un orden coercitivo) es porque considera que el antagonismo económico -que reduce a su vez el antagonismo de clase- es la única raíz relevante del comportamiento desviado y de la conflictividad social. Frente a tan sumario diagnóstico, la opinión kelseniana es que «lo que verdaderamente hace necesario un ordenamiento coercitivo» radica en ciertas constantes de la naturaleza humana situadas mucho más allá de la explotación económica de clase: se trata de «la oposición existente entre el ordenamiento social y los instintos, deseos e intereses de los

65 Id. (T.c.D.E., p. 65).

66 Id. (T.c.D.E., p. 65).

67 Justice et Droit naturel (1959) (cito por la trad. cast.: Justicia y Derecho natural en AAVV: Crítica del Derecho natural, introd. y trad. de Elías Díaz, Taurus, Madrid, 1966, p. 72).

$68 I d$., p. 70. 
hombres, cuyo comportamiento es regulado por el ordenamiento, para producir el estado de cosas querido por éste» ${ }^{69}$. Por ello, la misma supresión de la explotación de clase requiere, para que esta última no resurja, un orden coercitivo: pues «la explotación económica, no estando en la naturaleza de las cosas, puede surgir tan sólo de la naturaleza de los hombres y por consiguiente -si no se confía en la completa transformación del hombredeberá siempre ser impedida» ${ }^{70}$. Y esta confianza «en la completa transformación del hombre» -esto es, la predicción de que la supresión de la explotación habrá de generar una comunidad en la que los hombres actúen espontáneamente de forma solidaria en sus diversas relaciones mutuas- constituye, por su parte, «el ejemplo escolástico de una utopía 'no científica', por no estar basada en experiencia alguna» ${ }^{71}$. Antes al contrario, el conocimiento disponible abona más bien, según Kelsen, la predicción opuesta: pues «la psicología criminal demuestra que las circunstancias económicas no son las únicas causas de perturbación del orden social; que el sexo y la ambición representan un papel por lo menos tan importante como aquéllas, y quizá representen un papel más importante aún cuando sean eliminadas las causas económicas» ${ }^{72}$. Por todo ello, «sería una miopía incomprensible querer liquidar como meras diferencias factuales de opinión entre compañeros las dificultades que se presentan en el campo religioso, artístico y erótico, puesto que no existen divergencias de opinión que no puedan convertirse en un contraste de vida o muerte» ${ }^{73}$.

\section{7}

\section{La dictadura del proletariado}

7.1. A propósito de la tesis de la dictadura del proletariado, como etapa preparatoria de la futura sociedad sin Estado, cabe observar, ajuicio de Kelsen, un nuevo caso de contradicción interna en la doctrina marxista. Si en lo referente a la extinción del Estado la contradicción tenía lugar dentro de la vertiente programática de esta doctrina (sus programas político y económico serían mutuamente incompatibles) ahora la contradicción se daría entre una propuesta programática (la dictadura del proletariado) y la teoría explicativa del acontecer social propia del marxismo: el materialismo histórico o, como Kelsen significativamente prefiere decir, «la interpretación económica de la sociedad». Postular la dictadura del proletariado implica -argumenta Kelsen- abogar por la abolición de la explotación económica por medio de la dominación política, lo que resulta inconsistente con la explicación marxista de la dinámica social que, en la reconstrucción que el propio Kelsen hace de la misma, sostendría una relación de causalidad unidi-

69 T.G.D. e.m.s., p. 83.

70 Id., p. 84.

$71 S$ y E, p. 220.

72 La teoría comunista del Derecho (T.c.D.E., p. 65).

$73 S$ y E, p. 273. 
reccional entre economía y política. En la dictadura del proletariado escribe- «la clase políticamente dominante es, por lo menos en cierta medida, explotada por la clase políticamente dominada; y el proletariado es la clase políticamente dominante, pero la burguesía es, por menos en cierta medida, la clase económicamente dominante. Esto representa el abandono total de la interpretación económica de la sociedad» ${ }^{74}$.

7.2. Conviene advertir que cuando Kelsen señala la existencia de una contradicción entre la propuesta de la dictadura del proletariado y los esquemas interpretativos del materialismo histórico, el alcance del término 'dictadura del proletariado' se circunscribe -como se habrá observado en el texto que se acaba de citar- al de 'dominio de clase proletario' ${ }^{75}$, siendo indiferente para la cuestión cuales sean las formas políticas ('dictatoriales' o 'democráticas' en el sentido del uso común de estas expresiones) que tal dominio de clase asuma. A este respecto debe subrayarse -contra lo que algún crítico ha objetado ${ }^{76}$ - que Kelsen es perfectamente consciente de la peculiaridad del uso lingüístico marxiano del término 'dictadura', que no hace referencia a una configuración institucional 'despótica' del Estado, sino al carácter de clase del mismo. Véase, por ejemplo, el siguiente pasaje de Socialismo y Estado: «no puede caber duda de que Marx y Engels consideraron la democracia como la forma política en que se debía realizar la dictadura del proletariado. La palabra 'dictadura' no puede ser ciertamente muy afortunada [... pero] la conciliabilidad de la 'dictadura' en el sentido del uso lingüístico marx-engeliano, con la 'democracia' no puede ponerse en duda si se tiene presente la 'dictadura' de la burguesía, de la que habla Marx»" ${ }^{77}$. Y poco después: «yo no he afirmado nunca, como cree Max Adler, que exista una contradicción entre democracia y dictadura, en la forma en que Marx y Engels entienden este concepto (...). La contradicción existe únicamente entre la democracia y para ser más precisos, la reivindicada por Marx y En-

74 La teoría comunista del Derecho (T.c.D.E., p. 53). El mismo argumento se repite en The Foundations of the Democracy: «En la transición del régimen capitalista al socialista, la interpretación económica de la sociedad, con su principio de la supremacía de la economía sobre la política, se derrumba de forma manifiesta. Para llegar a ser el grupo económicamente dominante, es decir, para establecer un sistema económico socialista, el proletariado debe antes llegar a ser el grupo políticamente dominante» ( $I$ fondamenti della democrazia, cit., p. 329).

75 Qué signifique la expresión «dominio de clase proletario» es, por otra parte, problemático, «ya que según el sentido de la concepción materialista de la historia 'dominación' y ‘opresión' deberían tener sólo el significado económico de la explotación» ( $S$ y E, pp. 213-214). De ahí que se pueda concluir que se trata de una expresión vacía: «un dominio de clase sin explotación económica no tiene sentido» (Id., p. 215).

76 R. Guastini, en La dotrina pura del diritto e il marxismo, cit. en n. 20, cree ver en la crítica de Kelsen al marxismo una suerte de esencialismo lingüístico que entre otros efectos negativos, le impedirá comprender que, en el contexto del marxismo, «el sintagma 'dictadura democrática' -aún cuando suene como un abuso lingüístico- no es, en rigor, autocontradictorio» (p. 146). Sobre esta crítica de Guastini se volverá con detalle más adelante.

77 S y E, p. 320. 
gels tanto para el Estado de clase capitalista como para el proletario, y la dictadura tal como es concebida por la teoría bolchevique» ${ }^{78}$.

8

\section{Las teorías jurídicas del marxismo. El Derecho como ideología; el «Dere- cho revolucionario»}

8.1. La crítica de Kelsen a las teorías jurídicas del marxismo se desarrolla enteramente sobre las obras de los juristas soviéticos. El que ello sea así obedece a que en el período anterior a las mismas, el marxismo -como señala el propio Kelsen- «se había ocupado relativamente poco de los problemas de la teoría general del Derecho» ${ }^{79} \mathrm{y}$, en todo caso, no había dado a luz ninguna obra que se presentara como competitiva respecto a las teorías generales del Derecho elaboradas por autores «burgueses». El único libro importante de temática jurídica que produjo el marxismo pre-soviético fue el de Karl Renner Las instituciones del Derecho privado y su función social, pero este escrito -de nuevo en palabras de Kelsen- «no es propia o principalmente una crítica de la teoría burguesa del Derecho, sino una investigación sobre el Derecho burgués, sobre la función real y sobre los cambios de las funciones de sus institutos» ${ }^{80}$. La obra de Renner constituyó, pues, más una aportación externa y complementaria que una alternativa con vocación de disputar su propio terreno a las teorías generales del Derecho no marxistas.

Junto al tomar a los juristas soviéticos como blanco de referencia casi exclusivo, la crítica kelseniana al marxismo jurídico presenta otra particularidad digna de mención en relación con sus críticas filosóficas o teóricopolíticas: mientras que en el plano filosófico Kelsen se refiere casi invariablemente al marxismo in toto y en el plano teórico-político tan sólo tiene presente la gruesa dicotomía entre marxistas revolucionario/extincionistas y marxistas reformista/estatalistas, en sus críticas a las teorías jurídicas del marxismo aborda autor por autor y -salvo alguna excepción referente a

78 Id., p. 335 n. Ello no obstante, en Marx y Engels ya habría una cierta tendencia -luego radicalizada en la doctrina bolchevique- a desplazar el significado del término 'démocracia' hacia el contenido del orden jurídico, ubicando en un lugar algo secundario la forma de creación del mismo (Cfr., en este sentido, La teoría política del bolchevismo -T.c.D.E., pp. 324-326- e I fondamenti della democrazia, cit., pp. 192 y 328).

79 T. G. D. e m. s., p. 58

$80 I d$., pp. 58-59. Ello no obstante, N. Leser ha puesto de relieve la existencia de importantes coincidencias entre Kelsen y Renner en el plano de la teoría del Derecho y de la teoría de la ciencia jurídica. Según Leser, dichas coincidencias serían principalmente las siguientes: a) la oposición al sincretismo metodológico y a la infiltración de la sociología en la jurisprudencia; b) la consideración de que la eficacia de las normas es de la incumbencia del economista y del sociólogo y queda fuera de la sistematización jurídica; c) la consideración de las nociones de «deber jurídico» y de «sanción» como eje de la teoría del Derecho y del «derecho subjetivo» como técnica prescindible; d) la derivación del derecho subjetivo del Derecho objetivo y no a la inversa (cfr. N. Leser: Hans Kelsen y Karl Renner, en AAVV, Teoría pura del Derecho y teoría marxista del Derecho, trad. cast. de E. Volkening, Temis, Bogotá, 1984, pp. 68-69). 
posiciones generalmente asumidas por la tradición marxista, que seguidamente veremos- los examina y discute separadamente.

8.2. Dos de las posiciones ampliamente difundidas entre los juristas marxistas, que Kelsen critica imputándolas al marxismo como tal, son especialmente destacables: la tesis del carácter ideológico del Derecho y el concepto de «Derecho revolucionario». En ambos casos se trata de posiciones ampliamente difundidas entre los marxistas, pero no unánimemente compartidas por ellos: como se sabe, la tesis del carácter ideológico del Derecho es explícitamente negada el menos por un autor importante (Stucka) en tanto que el concepto de «Derecho revolucionario» no tiene cabida alguna en una concepción como la de Pasukanis.

8.2.1. Según Kelsen, cabe hablar de «ideología» en dos sentidos: en el primero, «ideología» se identifica con «el mundo del espíritu» ${ }^{81}$-esto es, el mundo de los objetos ideales creados por los hombres- y se contrapone a la realidad natural. En este sentido amplísimo de «ideología», las normas jurídicas pertenecen obviamente a su dominio. En un segundo sentido -que Kelsen considera como «el más estricto y propio de la palabra, el único en que se debería hablar de ideología» ${ }^{82}$ - este término alude a una representación deformada de la realidad, deformación que viene generada por la presencia -consciente o inconsciente- de juicios de valor en el interior de un discurso que debiera articularse como puramente cognoscitivo. En este sentido propio de "ideología" es ideológica, por ejemplo, la jurisprudencia burguesa, cuando a la «interpretación del material (normativo) empíricamente dado» une «la tendencia a justificarlo éticamente, a disfrazarlo y ocultarlo oportunamente en caso de que esté en contradicción con el valor fundamental que opera como presupuesto, en la mayor parte de los casos no consciente, de este intento de legitimación» ${ }^{83}$.

Pues bien: los marxistas, al hablar del Derecho como fenómeno ideológico, obviamente no tratan de indicar su no pertenencia a la realidad natural, su ubicación en lo que Kelsen llama el «mundo del espíritu», sino que hacen centralmente referencia a su carácter deformador, falseador de la realidad. Esta consideración del Derecho como ideología -en el sentido «estricto y propio» del término- carece, en opinión de Kelsen, de sentido y se basa por completo en una confusión entre el Derecho y los discursos sobre el Derecho. Si la ideología es representación deformada de la realidad, el Derecho no puede ser «ideológico» por la misma razón por la que no puede ser «verdadero»: esto es, porque no está constituido por aserciones (verdaderas o valorativamente deformadas) acerca de cómo es la realidad, sino por prescripciones, que carecen de valor veritativo. Escribe así: «El Derecho no es una teoría como producto del conocimiento sino una institución social establecida por actos de voluntad» ${ }^{84}$. Por ello, «si la función carac-

\footnotetext{
81 T.G.D. e.m.s., p. 61.

82 Id., p. 63.

83 Id. p.
}

84 La teoría comunista del Derecho (T.c.D.E., p. 129). 
terística de la 'ideología' consiste en representar erróneamente la realidad, reflejar -como un espejo defectuoso- la realidad en forma torcida, ni el Derecho ni el Estado como instituciones sociales reales pueden ser ideologías. Sólo una teoría como función del pensamiento, no el Derecho, que es una función no del pensamiento sino de la voluntad, puede ser una ideología (...). La opinión de que el Derecho es una ideología es el resultado de confundir el Derecho como una cierta teoría del Derecho, confusión que es muy frecuente no sólo entre los jurisconsultos marxistas, sino también entre los burgueses» ${ }^{85}$.

8.2.2. Otro sinsentido generalizado entre los juristas marxistas es, en opinión de Kelsen, su consideración del Derecho soviético como «Derecho revolucionario». El concepto de «Derecho revolucionario» es autocontradictorio, pues «Derecho» $\mathrm{y}$ «revolución» son términos incompatibles: «revolución -escribe- significa subversión, significa ruptura de un ordenamiento, significa discontinuidad, fundación de un nuevo ordenamiento sobre la violación del viejo, significa, por ello, ilegalidad» ${ }^{86}$. Esta incurrencia de los juristas marxistas en la contradictio in adjecto que implica la expresión «Derecho revolucionario» sólo se explica, a juicio de Kelsen, si se atiende a que en el uso marxista del término «revolución» no subyace propiamente un concepto, sino mas bien un slogan al que se otorga la máxima fuerza legitimante: los juristas de esta tendencia «se sirven de una nueva ideología, que en nada va a la zaga de la vieja en cuanto a fuerza de justificación [...]. A nadie que examine sin prejuicios el uso que la teoría marxista hace de las palabras 'revolución' y 'revolucionario' puede escapársele que con ellas no se expresa otra cosa más que un supremo valor social. Todo lo que el racionalismo burgués ve de valioso en la idea de progreso y el irracionalismo burgués en la idea de sagrado se concentra en la idea de revolución, tal como es presentada por la teoría marxista» ${ }^{87}$.

Stucka

La obra de Stucka La función revolucionaria del Derecho y del Estado: una teoría general del Derecho, publicada en 1921, significó, a juicio de Kelsen, «la primera tentativa importante de desarrollar una teoría del Derecho específicamente soviética -no como un simple subproducto de la teoría del Estado» ${ }^{88}$. Del examen kelseniano de la misma, tienen interés dos géneros de observaciones: las referentes a la definición de Derecho propuesta por Stucka y las formuladas a propósito de las críticas de éste a la jurisprudencia «burguesa».

El Derecho, como se sabe, es definido en la obra de Stucka como «un sistema (u ordenamiento) de relaciones sociales correspondiente a los intere-

85 Id. (T.c.D.E., p. 32).

86 T.G.D. e m.s., p. 101.

87 Id., p.

88 La teoría comunista del Derecho (T.c.D.E., p. 95). 
ses de la clase dominante y tutelado por la fuerza organizada de esta clase» ${ }^{89}$. Aclara Stucka que las «relaciones sociales» a que alude su definición se identifican con las relaciones económicas, y muy especialmente con las relaciones de producción. «Esto significa -observa Kelsen- que el Derecho se identifica con la sociedad y la sociedad con la economía» ${ }^{90}$. Esta disolución de la forma jurídica en las relaciones sociales (que no se consideran reguladas, sino meramente expresadas por aquélla) debiera -arguye Kelsendesembocar en una pareja disolución de la jurisprudencia en la ciencia económica: pues «si el Derecho, como algo diferente de la economía no existe en realidad [...] es imposible una teoría del Derecho diferente de una teoría económica» ${ }^{1}$. Este paso, ineludible desde una asunción coherente de la definición de Derecho de Stucka, no es dado sin embargo por éste: «[...] no hay un Derecho diferente de las relaciones económicas. Pero, por otra parte, Stucka trata el Derecho como objeto real de una ciencia que él no identifica, al menos expresamente, con la ciencia económica» ${ }^{92}$.

El trabajo de Stucka es, por otra parte-siempre a juicio de Kelsenparticularmente deficiente en sus críticas a las teorías jurídicas no marxistas. Según Stucka, la jurisprudencia burguesa se caracteriza por partir de «un concepto puramente formal del Derecho» y por contemplar éste como «una categoría eterna» ${ }^{93}$. En opinión de Kelsen, esta caracterización es, por un lado «contradictoria consigo mismo» y, por otro, ofrece una imagen por completo distorsionada de la teoría jurídica contemporánea al propio Stucka. Es autocontradictoria porque «una teoría legal no puede ser formalista y al mismo tiempo definir el Derecho como una categoría eterna. La escuela [...] que trata de describir el Derecho como una categoría eterna, es decir, la doctrina del Derecho natural, es exactamente lo opuesto a una jurisprudencia formalista, y se dirige conscientemente contra el formalismo en jurispruducencia» ${ }^{94}$. Por lo demás, la crítica de Stucka se dirige «contra un enemigo imaginario», pues «la mayoría de los autores burgueses, en la época en que Stucka publicó su doctrina marxista del Derecho, no seguían por cierto la doctrina del Derecho natural y no consideraban por cierto al Derecho como una categoría eterna. Insistían, e insisten aún, en oposición a la doctrina del Derecho natural, en el carácter histórico y cambiante del Derecho» ${ }^{95}$.

89 P. I. Stucka: La función revolucionaria del Derecho y del Estado, trad. y prólogo de J. R. Capella, Península, Barcelona, 1969, p. 24. Esta definición fue adoptada como «oficial», en 1918, por el Comisariado del Pueblo para la Justicia.

90 La teoría comunista del Derecho (T.c.D.E., p. 96).

$91 \mathrm{Id}$.

92 Id.

93 P. I. Stucka: Op. cit., p. 35.

94 La teoría comunista del Derecho (T.c.D.E., p. 108).

$95 \mathrm{Id}$. 


\section{0}

\section{Rejsner}

En el $\S 8$ se han examinado las críticas que Kelsen dirige al marxismo in genere a propósito de la tesis del carácter ideológico del Derecho. La concepción del Derecho de Rejsner representa una versión particularmente fuerte de esta tesis: su «remodelación de la doctrina de Petrazitsky sobre el Derecho intuitivo en el sentido de colocarla sobre cimientos marxistas»" ${ }^{96}$ desemboca en una definición de 'Derecho' en la que éste queda reducido a fenómeno entera y exclusivamente ideológico: el Derecho sería, sin más, «una ideología que se apoya, dentro de nuestra consciencia, fundamentalmente sobre el concepto de verdad, justicia e igugaldad en la distribución y en la igualación de los hombres y de las cosas» ${ }^{97}$. Las críticas que Kelsen dirige a Rejsner son, a este respecto, inevitablemente reduplicativas de las que ya vimos en el $\S 8$ dirigidas a los marxistas en general: el error básico de la teoría de Rejsner -escribe- reside en «la identificación de cierta teoría, interpretación o estimación de un objeto real con ese objeto; de una teoría del Estado con el Estado, de una teoría del Derecho con el Derecho» ${ }^{98}$.

Hay, sin embargo, ajuicio de Kelsen, un elemento estimable en la obra de Rejsner: su entendimiento de la transformación social auspiciada por el marxismo como proyecto normativo/valorativo y no, naturalistamente, como mero resultado de leyes histórico-causales. Pero este mérito del enfoque de Rejsner no pertenece, como es claro, propiamente a su teoría jurídica, si bien con él mantiene relación el concepto político-jurídico fundamental de este autor: la «conciencia jurídica revolucionaria» que -si bien posee perfiles tan nebulosos como, pongamos por caso, el «espíritu del pueblo» de la Escuela Histórica- fue de indudable funcionalidad en los primeros tiempos revolucionarios.

Mayor interés -por lo que puede resultar de revelador de algunos límites de la comprensión kelseniana de las teorías jurídicas marxistas- tiene el comentario que Kelsen dedica a la fórmula de Rejsner en la que éste alude al Derecho «como forma ideológica basada en la igualdad de lo desigual» ${ }^{99}$. Prescindiendo ahora de la referencia a la «forma ideológica», Rejsner se limita aquí a enunciar la tesis, común a los marxistas, de que el Derecho, regulando igualitariamente situaciones materialmente desiguales, garantiza la reproducción de la desigualdad. Pues bien, el comentario de Kelsen es el siguiente: «La frase 'Derecho como forma ideológica basada en la igualdad

96 Así explicaba el propio Rejsner el alcance de su teoría jurídica, en la obra publicada en 1925 El Derecho, nuestro Derecho, el Derecho extranjero, el Derecho general (cito por la traducción inglesa de Hugh W. Babb -Law, Our Law, Foreign Law, General Law- que figura en J. N. Hazard: Soviet Legal Philosophy, Harvard University Press, 1951, p. 85. Esta traducción es también la utilizada por Kelsen).

97 M. A. Rejsner: El Estado (1912), citado por el propio Rejsner en El Derecho, nuestro Derecho, el Derecho extranjero, el Derecho general (trad. inglesa cit., p. 89).

98 La teoría comunista del Derecho (T.c.D.E., p. 122).

99 M.A. Rejsner: op. cit., p. 107. 
de lo desigual' no tiene otra función que oscurecer el hecho de que el Derecho no se basa en la igualdad de lo desigual sino que hay una teoría del Derecho que lo presenta como Derecho de igualdad aunque es un Derecho de desigualdad» ${ }^{00}$.

\section{1}

\section{Pasukanis}

E. B. Pasukanis es, en opinión de Kelsen, «el representante más prominente de la teoría jurídica soviética en el primer período de su desarrollo» ${ }^{101}$. La importancia concedida por Kelsen a Pasukanis no se manifiesta solamente en este reconocimiento explícito, sino también en la atención prestada a su obra, cuidadosamente diseccionada tanto en La teoría general del Derecho y el materialismo histórico de 1931 (cuyo eje central viene a ser, precisamente, una prolija discusión con Pasukanis) como en La teoría comunista del Derecho de 1955. Y -lo que es sin duda menos objetivable pero quizás más indicativo- el tono general de discurso de Kelsen es notablemente diferente cuando es Pasukanis y no cualquier otro de los juristas soviéticos el objeto de su crítica: cuando ésta versa sobre Rejsner, Stucka o Vysinskij, el lector no puede evitar la impresión de que Kelsen está realizando una tarea que él mismo considera intelectualmente rutinaria; Pasukanis, en cambio, parece provocarle verdadera pasión.

El Derecho es presentado en la obra de Pasukanis como «la forma mistificada de una relación social específica» ${ }^{102}$ : la relación entre poseedores de mercancías que intercambian equivalentes. De ello se deriva que «el núcleo más sólido de la nebulosa jurídica está precisamente en el campo de las relaciones de Derecho privado» ${ }^{103}$ en tanto que el Derecho público sólo cabe hablar impropiamente, pues «el Estado (...) no necesita interpretación jurídica e incluso sustancialmente no la permite. Es un dominio en el que reina la llamada raison d'État que no es otra cosa que el principio de la simple conformidad con el fin» ${ }^{104}$. Por otra parte, en la concepción del Derecho de Pasukanis el elemento fundamental del mismo es la relación jurídica y no la norma: «la norma como tal [...] -escribe- o bien es una inferencia de relaciones ya existentes, o bien no representa, cuando es formulada como ley estatal, más que un síntoma que permite prever con una cierta verosimilitud el futuro nacimiento de las relaciones correspondientes» ${ }^{105}$. Consideración, pues, del Derecho como expresión de las relaciones mercantiles y de la relación jurídica como elemento primario del Derecho.

100 La teoría comunista del Derecho (T.c.D.E., p. 127).

101 La teoría comunista del Derecho (T.c.D.E., p. 131).

102 E. B. Pasukanis: Teoría general del Derecho y marxismo (1924), trad. cast. y presentación de V. Zapatero, Labor, Barcelona, 1976, p. 65.

103 Id., p. 66.

104 Id., p. 117.

105 Id., p. 74. 
Las críticas de Kelsen a la teoría jurídica de Pasukanis -aquí sumarísimamente bosquejada en sus determinaciones más básicas ${ }^{106}$ - pueden reconducirse, en mi opinión, a los puntos siguientes:

11.1. La identificación del Derecho con las relaciones entre poseedores de mercancías impide a Pasukanis dar cuenta de un buen número de relaciones asimismo jurídico-privadas, como, por ejemplo, las pertenecientes al Derecho de familia: «Es evidente -anota Kelsen- que en el Derecho de una sociedad capitalista (que Pasukanis toma como el Derecho par excellence) no sólo las relaciones entre poseedores de mercancías tienen el carácter de relaciones jurídicas, sino también otras, como la relación entre marido y mujer, o entre padres e hijos, que pueden existir igualmente en una sociedad comunista» ${ }^{107}$.

11.2. Uno de los reproches fundamentales de Pasukanis a las teorías jurídicas marxistas anteriores a la suya reside en que en ellas «el concepto jurídico es considerado exclusivamente desde el punto de vista de su contenido; no se plantea en absoluto el problema de la forma jurídica como tal» ${ }^{108}$. Pasukanis se propone superar esta carencia, considerando que «la teoría marxista debe, no solamente analizar el contenido material de la reglamentación jurídica en las diferentes épocas históricas, sino dar, además, una explicación materialista a la misma reglamentación jurídica en cuanto forma históricamente determinada» ${ }^{109}$. Sin embargo, este intento de superar la disolución de lo jurídico que critica en otros marxistas es, a juicio de Kelsen, irrealizable desde la propia concepción del Derecho de Pasukanis: si se considera que el Derecho es primariamente relación y no norma, lo específicamente jurídico se desvanece necesariamente; el precio de descartar la norma como eje del universo jurídico es precisamente el de no poder dar cuenta de la forma jurídica como tal. Escribe, en este sentido, Kelsen: «Aún si aceptamos esta artificial limitación del concepto de Derecho y suponemos que sólo las relaciones entre poseedores de mercancías son relaciones jurídicas o, como lo formula Pasukanis, asumen la 'forma' de relaciones jurídicas, 'reflejan' la 'forma del Derecho' surge la pregunta: ¿qué es esta 'forma del Derecho'? No puede ser idéntica a la relación económica específica que 'refleja'. Pero Pasukanis no contesta ni puede contestar a esta pregunta $[\ldots] \gg$. ${ }^{10}$.

11.3. Una acusación que Kelsen dirige una y otra vez a Pasukanis es la de que éste se sitúa invariablemente «del lado de la tendencia ideológica y contra la tendencia antiideológica» de la jurisprudencia burguesa en una serie de puntos capitales de desacuerdo entre ambas: «tendencia ideológica» $\mathrm{y}$ «tendencia antiideológica» deben, naturalmente, entenderse en este con-

106 Para una exposición más circunstanciada de la teoría jurídica de Pasukanis, remito al artículo, escrito conjuntamente con M. Atienza, Marxismo y ciencia del Derecho, en «Sistema», n. ${ }^{\circ}$ 64, esp. pp. 8-17.

107 La teoría comunista del Derecho (T.c.D.E., p. 135).

108 E.B. Pasukanis: op. cit., p. 42.

109 Id.

110 La teoría comunista del Derecho (T.c.D.E., p. 135-136). 
texto como sinónimos, respectivamente, de «teoría tradicional» (o no kelseniana) y «teoría pura» (kelseniana) del Derecho. Esta alineación de Pasukanis con la «tendencia ideológica» se refleja sobre todo en su aceptación de una serie de dualismos característicos de ésta (Derecho público/Derecho privado, Derecho objetivo/derecho subjetivo, Estado/Derecho) y también en algún otro elemento de su teoría del Derecho como, muy especialmente, su entendimiento del Derecho penal en términos retribucionistas.

11 .3.1. La negativa a conceder carácter jurídico al Derecho público «no es de ningún modo -señala Kelsen- una doctrina específicamente marxista. Muchos autores burgueses y especialmente juristas alemanas de actitud netamente conservadora defendieron esa doctrina» ${ }^{111}$. De hecho, la distinción romanística entre Derecho público y Derecho privado fue adoptada por la jurisprudencia alemana en beneficio de los príncipes reinantes y, por consiguiente, «no tanto en nombre del Derecho privado romano, sino más bien en nombre del Derecho romano del Estado, cuya teoría culminaba en la fórmula: princeps legibus solutus est» ${ }^{112}$. Así, la distinción entre Derecho público y Derecho privado conduce siempre a la difuminación del carácter jurídico del primero: en los autores dualistas, «el Derecho 'público' viene a ser Derecho sólo en sentido impropio, viene a ser un ámbito en el que, por así decirlo, el pensamiento jurídico produce sus efectos con menos intensidad. El Derecho privado es el ámbito propio del Derecho» ${ }^{113}$. Esta difuminación del carácter jurídico del Derecho público y la consiguiente afirmación de que «sólo el Derecho privado es verdadero Derecho» cumplen dos importantes funciones ideológicas: la primera es la de «justificar actos de gobierno, si por razones políticas el gobierno no aplica el Derecho existente, que le impone ciertas obligaciones» " pecialmente sensible el marxista Pasukanis- es la de presentar las relaciones jurídico-privadas (por ejemplo, la que une al trabajador asalariado con su patrono) como ubicadas en un campo «del que parece excluido todo dominio político» ${ }^{115}$ ocultando el hecho de que «si el Estado no tuviera obligaciones jurídicas, no podría haber derechos de los individuos; de que no hay relación jurídica en la que no sea parte -directa o indirectamente- el Estado, de modo que todo el Derecho es por su propia naturaleza Derecho público $[. ..] \gg{ }^{116}$.

De esta forma, Pasukanis, al circunscribir el ámbito de lo jurídico al Derecho privado «no describe ni el Derecho en general ni el Derecho de una sociedad capitalista [sino que] reproduce una doctrina burguesa del Dere-

111 Id., (T.c.D.E.), p. 138.

112 T.G.D. e m. s., p. 145.

113 Id., p. 148.

114 La teoría comunista del Derecho (T.c.D.E., p. 140).

115 T.G.D. em.s., p. 133.

116 La teoría comunista del Derecho (T.c.D.E., p. 139). 
cho, errónea por ideológica» ${ }^{117}$ y, así, «lleva agua al molino de quienes pretende combatir» ${ }^{118}$.

11.3.2. La misma alineación con la «tendencia ideológica» muestra Pasukanis al aceptar el dualismo Derecho objetivo/derecho subjetivo y al conceder, dentro de él, la primacía a este último. La función ideológica de esta dicotomía es, en opinión de Kelsen, la de poner determinados límites al contenido posible del ordenamiento jurídico presentando al contenido posible del ordenamiento jurídico presentando los derechos subjetivos (y «ante todo la propiedad, ese prototipo del derecho subjetivo» ${ }^{119}$ ) como un prius respecto del Derecho objetivo que, así, no podría sino reconocer y garantizar estos derechos subjetivos surgidos independientemente de él: «se trata escribe Kelsen- de defender la idea de que el derecho subjetivo, y más precisamente la propiedad privada, es una categoría a priori y trascendente respecto al Derecho objetivo, es una institución frente a la cual la conformación del contenido del ordenamiento jurídico encuentra una barrera infranqueable» ${ }^{120}$; en el mismo sentido: «el único propósito de esta interpretación dualista del Derecho es garantizar los derechos subjetivos existentes [...] especialmente los derechos de propiedad [...] para impedir la expropiación sin indemnización en caso de una reforma del Derecho existente, argumentando que tal reforma sería contraria a la naturaleza del Derecho» ${ }^{91}$. Frente a esta construcción ideológica, la teoría pura del Derecho reconduce, como se sabe, el derecho subjetivo al ordenamiento jurídico objetivo, lo que le permite mostrar que «el derecho subjetivo es sólo una posible y de ninguna manera necesaria conformación del contenido del Derecho objetivo, una técnica particular, de la que el Derecho puede servirse pero no es un absoluto necesario que se sirva» ${ }^{122}$. En opinión de Pasukanis, la teoría pura representaría en este punto «el espíritu de la época en que la escuela Manchester y la libre competencia fueron reemplazados por los grandes monopolios capitalistas y la política imperialista», y la primacía que el sistema kelseniano otorga al Derecho objetivo no pasaría de ser un reflejo del hecho de que «el capital financiero aprecia mucho más el poder fuerte y la disciplina que no los 'eternos e intangibles derechos del hombre y del ciudadano'» ${ }^{123}$. Lejos de ello, lo cierto es -argumenta Kelsen- que su construcción teóricojurídica, al mostrar el derecho subjetivo como una técnica normativa prescindible «excluye todo abuso ideológico» respecto al mismo y deja expedita la vía para poner de relieve su vinculación con el sistema capitalista: el derecho subjetivo -indica expresamente- «es la técnica específica del ordenamiento jurídico capitalista, en cuanto que está construido sobre la institu-

117 Id., (T.c.D.E.), p. 140.

118 T.G.D. e m.s., p. 149.

119 Id., p. 119.

120 Id., p. 122.

121 La teoría comunista del Derecho (T.c.D.E., p. 142).

122 T.G.D. em.s., p. 129.

123 Teoría general del Derecho y marxismo, cit., p. 84. 
ción de la propiedad privada y, por consiguiente, tiene particularmente en cuenta el interés individual»

En el mismo sentido que la dicotonomía Derecho objetivo-derecho subjetivo se mueve, a juicio de Kelsen, la distinción -común en la doctrina tradicional y asimismo aceptada por Pasukanis- entre relaciones jurídicas personales y reales. Lo deformante de esta distinción se halla en la pretensión de que, junto a las relaciones jurídicas entre sujetos de Derecho, habría relaciones jurídicas de otro tipo (las denominadas relaciones reales y muy especialmente -de nuevo- la propiedad) cuyos dos polos estarían constituidos por un sujeto y un objeto de Derecho, una persona y una cosa. Pues bien: el instituto de la propiedad - «la relación jurídica real por excelencia, a la que se refiere toda la distinción» ${ }^{125}$ - no consiste, indica Kelsen, en una relación entre hombre y cosa, sino en una «relación entre hombre y hombre, [una] relación de exclusión de todos los demás de una esfera de intereses garantizada de esta forma a uno sólo» ${ }^{126}$. Si la doctrina jurídica conserva la noción de relación jurídica real y sigue entendiendo la propiedad en términos de una relación de este género, ello se debe enteramente a motivos de enmascaramiento ideológico: a saber, que «la definición de la propiedad como relación entre persona y cosa oculta la función económicamente decisiva de la propiedad, la función de la explotación» ${ }^{127}$. Pasukanis, que acepta el concepto de relación jurídica real al recurrir, para explicar la propiedad, a la «historia prejurídica», el «principio organito o naturalístico de la apropiación privada», no hace así sino entregarse «de forma completamente acrítica a una de las más peligrosas doctrinas jurídicas burguesas» ${ }^{128}$.

11.3.3. Un último dualismo característico de la «tendencia ideológica» de la jurisprudencia burguesa y asumido en la obra de Pasukanis es el que distingue entre Estado y Derecho. El entendimiento del Estado como entidad distinta del ordenamiento jurídico cumple, según Kelsen, la función ideológica de posibilitar que «el Derecho pueda justificar al Estado que genera este Derecho y que se somete a él». Pues «el Derecho puede justificar al Estado sólo si aquél se entiende como un ordenamiento distinto en su esencia del Estado, opuesto a su naturaleza originaria, el poder, y por ello como un ordenamiento en cierto sentido justo» ${ }^{129}$. Si por el contrario, como postula la teoría pura, se identifican Derecho y Estado, definiendo éste como ordenamiento social coactivo, la posibilidad de legitimar el Estado por medio del Derecho - «la ideología de la legitimación hoy más eficaz» ${ }^{130}$ - se desvanece. Por lo demás, el mantenimiento de la distinción entre Estado y Derecho, combinada con la definición del Derecho como forma del inter-

124 T.G.D. e m.s., p. 129.

125 Id., p. 124.

126 Id., p. 159.

127 Id., p. 124-125.

$128 I d .$, p. 161.

129 Id., p. 168.

130 Id., p. 171. 
cambio mercantil produce consecuencias que desde la perspectiva del marxismo no pueden calificarse sino de disparatadas: «el marxista que acepta acríticamente esta construcción dualista deberá distinguir el poder como organización del dominio de clase del poder como garante del intercambio mercantil, como si la organización del dominio de clase no se mantuviera precisamente a través de la garantía del intercambio mercantil» ${ }^{131}$.

11 3.4. La concepción del Derecho penal de Pasukanis es probablemente el componente más artificioso de su teoría jurídica. Dicha concepción es el resultado de tratar de amoldar al Derecho penal -al que Pasukanis no se atreve a negar carácter jurídico- la definición del Derecho como forma del intercambio mercantil. Desde esa premisa, Pasukanis no puede entender el Derecho penal más que, en términos retribucionistas, como un «intercambio de culpa y pena». Al hacerlo así, el jurista soviético identifica, una vez mas, «el Derecho objetivo-real con una teoría ideológico-subjetiva del Derecho» ${ }^{132}$. Teoría ideológica, además, propia de «los más reaccionarios teóricos burgueses» ${ }^{133}$ y ya abandonada por la generalidad de éstos en beneficio de la teoría de la prevención.

11.4. La contraposición entre «norma jurídica» y «regla técnica» es de gran importancia en la teoría de Pasukanis y, en particular, en la forma como en ella se presenta la tesis de la extinción del Derecho en la sociedad socialista plenamente desarrollada. La diferencia entre ambos tipos de reglas la sitúa Pasukanis en lo siguiente: mientras que la norma jurídica tiene como presupuesto fundamental el antagonismo de intereses privados, la reglamentación técnica presupone la unidad de fines. De esta forma, mientras que, por ejemplo, las normas que regulan la responsabilidad de los ferrocarriles son normas jurídicas, porque «presuponen exigencias privadas, intereses privados diferenciados», las disposiciones relativas al tráfico de los mismos son reglas técnicas en cuanto «presuponen un fin unívoco que no es más que la consecución de la máxima capacidad de transporte» ${ }^{134}$. Es importante advertir que la nota de la coactividad es irrelevante para la distinción entre «norma jurídica» y «regla técnica»: así, por ejemplo, la relación médico/enfermo supone cierta constricción con respecto al enfermo, pero dado que «esta constricción es considerada desde el punto de vista de un mismo fin (idéntico para quien la ejercita y para quien la padece) no es más que un acto que tiene una finalidad técnica y nada más» ${ }^{135}$.

La distinción así diseñada permite a Pasukanis admitir la persistencia de reglas coactivas en la sociedad socialista y negar, al tiempo, que tales reglas coactivas tengan carácter jurídico: pues la sociedad socialista se caracteriza, precisamente, por la desaparición de los antagonismos de intereses entre los hombres y por la comunidad de fines de todos ellos.

131 Id., p. 172-173.

132 Id., p. 112.

$133 I d$.

134 Teoría general del Derecho y marxismo, cit., p. 67.

$135 I d$. 
La crítica de Kelsen se desarrolla, aquí, a un doble nivel. En primer lugar, señala que la presuposición de una unidad de fin entre quien ejercita la coacción y quien la sufre «es una ficción evidente» que «puede significar sólo que la sociedad comunista, al ejercer compulsión contra un miembro recalcitrante, lo hace en el verdadero interés de ese miembro, aunque éste no lo comprenda y deba por tanto ser compelido» ${ }^{136}$; esta ficción legitimante no es, por otra parte, precisamente novedosa: «una escuela ideológica de jurisprudencia burguesa sostiene exactamente lo mismo con respecto al castigo del delincuente por un órgano del Estado capitalista» ${ }^{137}$. En segundo lugar, la propia oposición entre ordenamiento jurídico y reglamentación técnica carece de sentido «porque el Derecho, si no se lo mira a través de los cristales de color de una ideología burguesa o proletaria, capitalista o socialista, es por su propia naturaleza una técnica, una técnica social específica» ${ }^{138}$.

\section{2}

\section{Vysinskij}

La construcción de Pasukanis, con su ignorancia del momento normativo del Derecho y su reducción de éste a las relaciones burguesas de intercambio, no era apta para representar, en el plano de la teoría jurídica, el punto de vista de un poder soviético consolidado que, en los hechos, estaba lejos de considerarse a sí mismo como un fenómeno transitorio de breve duración. Un poder soviético con vocación de afirmación y de permanencia exigía -escribe Kelsen- «una teoría jurídica que reconociera la autoridad del Estado soviético, lo cual significa el carácter normativo, la fuerza obligatoria de su Derecho, así como un orden jurídico específicamente socialista, y no un mero vestigio del Derecho burgués» ${ }^{139}$ : en definitiva, una teoría normativa del Derecho que entendiera éste como un instrumento adecuado para moldear las relaciones sociales de acuerdo con la voluntad de sus edictores.

La teoría de Vysinskij había de ser la respuesta a esta exigencia. Y ello explica, en buena medida, la actitud de Kelsen frente a la misma, que viene a ser justamente el reverso de la adoptada frente a Pasukanis. El hecho de que el normativismo de Vysinskij obedeciera, no a intereses de conocimiento del Derecho, sino a espurias razones políticas, así como la personalidad general del fiscal de Stalin, irritan visible y profundamente a Kelsen; mas, de otro lado, ese mismo normativismo vysinskijiano se encuentra -y esto, a su vez, suscita una evidente incomodidad en Kelsen- muy próximo a su propia concepción del Derecho. Si en el tratamiento dispensado a Pasukanis se combinan el reconocimiento de su talento y de la importancia de su

136 La teoría comunista del Derecho (T.c.D.E., pp. 151-152). En términos casi idénticos, T.G.D. e m.s.. pp. 94-95.

137 La teoría comunista del Derecho (T.c.D.E., p. 152).

138 Id., p. 152. De nuevo en términos casi idénticos TGD e m.s., p. 95.

139 Id., p. 159. 
obra con el desacuerdo y la crítica radicales de todos los puntos capitales de la misma, en el examen de Vysinskij la máxima aversión personal se da la mano con el acuerdo de fondo con sus posiciones -a las que sólo se reprocha su defectuosa formulación- en la determinación del más básico de los conceptos jurídicos.

Las críticas de Kelsen a Vysinskij -dejando momentáneamente al margen las relaciones con la definición de «Derecho»- son de tres tipos. En primer lugar, críticas a la sumisión tanto personal como intelectual de Vysinskij a los dictados stalinianos: a propósito, por ejemplo, del estilo literario de Vysinskij escribe Kelsen lo siguiente: «un servilismo repugnante hacia el entonces dictador, una postración intelectual que supera las peores formas del bizantinismo, son rasgos característicos de esta ciencia jurídica, cuya mayor ambición es ser una sumisa servidora del gobierno» ${ }^{140}$. En segundo lugar, críticas a la atribución, por parte de Vysinskij, de una función normativa a la teoría del Derecho. Vysinskij -hace notar Kelsen- no concibe la ciencia jurídica como limitada a la simple descripción del Derecho, sino que le adjudica también la tarea de suministrar criterios para el establecimiento de contenidos normativos: «la 'teoría del Derecho' en que piensa Vysinskij no es, sin duda, una teoría del Derecho positivo [...]. Según Vysinskij, la 'teoría jurídica' es el 'sistema de principios jurídicos' sobre cuya base habrá de establecerse el Derecho positivo del Estado socialista» ${ }^{141}$. En tercer lugar, críticas al carácter antimarxista del normativismo de Vysinskij y a su determinación por razones políticas: «Vysinskij llega hasta rechazar la parte de las teorías de aquellos [Stucka y Pasukanis] que era el resultado de la más ortodoxa sumisión al marxismo, o sea, la interpretación económica del Derecho, la reducción del Derecho a la economía» ${ }^{142}$; «no puede caber la más mínima duda de que la interpretación hecha por Pasukanis del Derecho soviético como Derecho burgués asimilado y adaptado, estaba en completo acuerdo con la doctrina de Marx» ${ }^{143}$; si Vysinskij insiste en «el carácter específico del Derecho como conjunto de reglas de conducta» y niega que el Derecho soviético tenga carácter de Derecho burgués, ello se debe simplemente a que «por razones políticas esta opinión no es ya aceptable para el gobierno soviético» ${ }^{144}$.

Ninguna de estas críticas -a pesar del tono de extrema dureza con el que está redactada- tiene por sí misma particular relevancia teórica: no la tiene, desde luego, al menos desde el punto de vista de Kelsen (otra cosa es, naturalmente, desde el de Vysinskij) la acusación de antimarxismo; en cuanto al considerar a la ciencia jurídica como normativa en cuanto a su función, se trata de una mera particularización de un rasgo característico del conjunto de la tradición marxista, y no sólo de Vysinskij: la no separación entre

140 Id., p. 179.

141 Id., pp. 170-171.

142 Id., p. 175.

143 Id., p. 176.

144 Id., p. 177. 
ciencia y política y la consiguiente ubicación del establecimiento de fines dentro del dominio de la ciencia; finalmente, por lo que hace a los móviles políticos de la teoría de Vysinskij, es sabido que la génesis de una teoría es asunto independiente del de su valor como tal teoría. Y así parece, por lo demás, aceptarlo Kelsen: pues cuando aborda el núcleo central de la teoría de Vysinskij -su definición de «Derecho»- atendiendo no a sus determinantes externos, sino a su pertinencia conceptual, sus críticas versan solamente sobre algunos defectos en la formulación de tal definición, pero no sobre el fondo de la misma. La definición de «Derecho» de Vysinskij -adoptada a propuesta suya por el Instituto de Derecho de la Academia de Ciencias soviéticas- es la siguiente: «El Derecho es el conjunto de reglas de conducta que expresan la voluntad de la clase dominante, establecidas en orden jurídico, así como de las costumbres y reglas de vida de la comunidad confirmadas por la autoridad del Estado, cuya aplicación está garantizada por la fuerza coactiva del Estado a fin de proteger, asegurar y desarrollar las relaciones y disposiciones sociales ventajosas y convenientes a la clase dominante» ${ }^{145}$. Las críticas de Kelsen a esta farragosa definición vienen a ser las siguientes: observa que, en su conjunto, «juzgada desde un punto de vista puramente lógico, causa la impresión de diletantismo»; que hay en ella tautologías tales como 'el Derecho es el conjunto de reglas (...) establecidas en orden jurídico', «pues con conjunto de reglas es un orden y orden jurídico es sólo otro nombre del Derecho»; pleonasmos, tales como: a) agregar a las 'reglas de conducta' las 'costumbres y reglas de vida de la comunidad confirmadas por la autoridad del Estado', «porque las 'costumbres' son reglas consuetudinarias y -lo mismo que las 'reglas de vida de la comunidad'con reglas de conducta»; b) añadir al carácter de "confirmadas por la autoridad del Estado', 'garantizadas por la fuerza coactiva del Estado', «lo cual significa exactamente lo mismo»; c) hablar de "proteger, asegurar («que es lo mismo que proteger») y desarrollar las relaciones y disposiciones ventajosas y convenientes («si son ventajosas son convenientes») a la clase dominante' ${ }^{146}$. Como puede verse, ninguna de estas críticas es propiamente sustantiva: bien al contrario, parece como si Kelsen hubiera procedido a redactarla con la precisa intención de suministrar una plena justificación para que alguien, veintitrés años más tarde, pudiera escribir que la definición de Derecho de Vysinskij «podría firmarla Kelsen, sin más sustitución que la de 'clase' por 'grupo', para salvar el alma, y la eliminación de algunas redundancias»

145 A. Y. Vysinskij: Las tareas fundamentales de la ciencia del Derecho socialista soviético (1983) (se cita por la trad. inglesa, a la que también se remite Kelsen, de Hugh W. $\mathrm{Babb}$-The fundamental tasks of the Science of Soviet Socialist Law-recogida en la antología de J. N. Hazard: Soviet Legal Philosophy, cit., p. 336. Esta definición había sido adoptada con anterioridad por el Instituto de Derecho de la Academia de Ciencias, a propuesta de Vysinskij.

146 La teoría comunista del Derecho (T.c.D.E., p. 182).

147 J. R. Capella: Derecho, política y poder social en el socialismo, prólogo a P. I. Stucka: La función revolucionaria del Derecho y del Estado, cit., p. 13. 


\section{3}

\section{Algunas críticas a la crítica de Kelsen}

En un trabajo reciente, U. Scarpelli ha escrito que, tras medio siglo de crítica a la teoría pura, lo que de verdaderamente importante queda de ella es «la propuesta de una teoría capaz de operar como estructura de base para la racionalización de la praxis en la jurisprudencia teórica y en la jurisprudencia práctica» ${ }^{148}$. Sobre la lectura por un jurista de los trabajos kelsenianos de crítica del marxismo gravita, creo, decisivamente la importancia capital que ha tenido la teoría pura para hacer avanzar el análisis de los conceptos básicos del Derecho y la comprensión de la estructura y la dinámica del ordenamiento jurídico. En este campo temático -que es el propio de la perspectiva del jurista- las aportaciones que desde la tradición marxista hayan podido hacerse aparecen inevitablemente, confrontadas con las de la teoría pura, como nimiedades. Nimiedades que, además, se presentan, en muchos casos, prisioneros de aparatos conceptuales que la ciencia jurídica actual ha dejado de lado precisamente como pre-kelsenianos.

Si la teoría jurídica relevante en la actualidad es decididamente postkelseniana (en el sentido, como decía J. R. Capella, de que si vemos más lejos que él es porque estamos montados sobre sus hombros) ${ }^{149}$ la cultura filosófica hoy predominante se encuentra también más cerca de los presupuestos de Kelsen que de los del marxismo (al menos en su versión clásica): en el sentido de que la reflexión filosófica que hoy cuenta es deudora en mucha mayor medida -por decirlo un tanto sumariamente- de las tradiciones que se remontan a Hume y a Kant que de la inaugurada por Hegel.

Aún desde los límites que vienen marcados por esta doble perspectiva -postkelsenismo en la teoría del Derecho, orientación filosófica vinculada a las tradiciones de Hume y Kant- caben, a mi juicio, diversas críticas a la crítica kelseniana del marxismo. Algunas de ellas afecta a aspectos de la interpretación kelseniana de la doctrina criticada; otras, a ciertas inconsistencias que exhibe la crítica kelseniana en relación con postulados epistemológicos y metodológicos claves en la obra del propio Kelsen; otras, en fin, a algunas debilidades sustantivas que presenta la aproximación a determinados problemas por parte de Kelsen.

No entro a considerar aquí la eventual fecundidad que pudiera tener -para el examen crítico de los trabajos de Kelsen sobre el marxismo- la adopción de perspectivas mas externas, esto es, sustentadas en presupuestos más distantes de los del propio Kelsen.

13.1. No cabe duda, a mi juicio, de que la interpretación kelseniana de la concepción ética de Marx en términos naturalistas tiene un sólido fundamento en la obra de Marx. Son numerosos los textos de éste en los que, en efecto, el deber ser de nuevas formas de organización social (el socialismo

148 U. Scarpelli: La crítica analítica a Kelsen, en AAVV Hans Kelsen nella cultura filosoficogiuridica del Novecento, Istituto della Enciclopedia Italiana, Roma, 1983, p. 75.

149 J. R. Capella, Homenaje a Hans Kelsen, en Materiales para la crítica de la filosofía del Estado, Fontanella, Barcelona, 1976, p. 192. 
y el comunismo) no tiene más apoyatura que su proclamada inevitabilidad: el socialismo y el comunismo deben ser simplemente porque serán. Tampoco cabe duda de que esta reducción de los valores al plano de la facticidad ha sido predominante en la tradición marxista: piénsese en un Kautsky, un Plejánov o un Lenin. En todos ellos, el deber se presenta como deducido de la necesidad; la valoración moral no tiene otro fundamento que el conocimiento de pretendidas leyes históricas, al que se añade, como mucho, un utilitarismo bastante crudo. Incluso hoy asombra ver cómo algunos marxistas, pretendiendo criticar a Kelsen al respecto, se limitan a volver a enunciar aquello que Kelsen critica, sin suministrar argumento alguno que permita poner en cuestión la pertinencia de la crítica kelseniana. Tal es el caso, por ejemplo, de F. Russo cuando escribe: «lo que a Kelsen le parece un sincretismo metodológico -el hecho de que la descripción de la sociedad sea inmediatamente propuesta ético-política- es el fruto, por el contrario, del análisis de los fundamentos de la realidad capitalista» ${ }^{150}$. Cómo pueda derivarse una propuesta ético-política de la descripción o el análisis de realidad alguna es algo que, naturalmente, Russo no explica. Como tampoco lo hace A. Pfabigan, quien se limita al expediente de apelar a las virtualidades -tampoco explicadas- del «método dialéctico». Escribe así Pfabigan: «opina Kelsen que al político que quiera saber qué debe hacer, sólo puede darle el marxismo una respuesta en extremo insatisfactoria, diciéndolo lo que será. Un marxismo de tal jaez, en efecto, se vería enfrentado al problema de justificarse como teoría política. Más en virtud de su método dialéctico, el marxismo no necesita semejante legitimación» ${ }^{151}$. Todo un prodigio -como puede verse- de escamoteo de la argumentación en beneficio de la petición de principio.

No obstante todo ello, hay también que subrayar que no todos aquellos que se han considerado a sí mismo insertos en la tradición marxista han aceptado una concepción naturalista de la ética. Limitándonos a corrientes particularmente próximas al universo cultural de Kelsen, no fueron, desde luego, naturalistas en ética quienes -partiendo, bien del neokantismo, bien del marxismo- preconizaron completamente a Marx con Kant: en el sentido de considerar el materialismo histórico como un discurso en indicativo dirigido al conocimiento de la dinámica de la realidad social que debía ser completado (y de ahí el recurso a Kant) con un discurso ético-normativo que fundamentase el socialismo como programa, esto es, como objetivo valioso. Es, a mi juicio, absolutamente sorprendente que Kelsen no haya considerado necesario, en ninguna de sus obras sobre el marxismo, echar las cuentas con este, según los casos, kantismo marxistizado o marxismo kantianizado ${ }^{152}$,

150 F. Russo: Kelsen e il marxismo. Democrazia politica o socialismo, La Nuova Italia, Florencia, 1976, p. 31. Sobre este libro de Russo véase la durísima crítica de I. Villarolo, publicada con el título de Né Kelsen né il marxismo, en «Politica del Diritto», n. ${ }^{\circ}$ 4, 1977, pp. 471-475.

151 A. Pfabigan: La polémica entre Hans Kelsen y Marx Adler sobre la teoría marxista del Estado, en AAVV: Teoría pura del Derecho y teoría marxista del Derecho, cit., p. 84.

152 Los textos más significativos de esta corriente se encuentran en trad. castellana en la antología preparada por V. Zapatero: Socialismo y ética: textos para un debate, PlumaDebate, Bogotá-Madrid, 1980. 
sobre todo si se tiene en cuenta que estos intentos de unión entre Kant y Marx procedieron de medios intelectuales muy próximos a aquéllos en los que estuvo inmerso el primer Kelsen.

13.2 Aún sin entrar en la -entre los marxistas- disputadísima cuestión de cuáles son los elementos hegelianos que pueden considerarse incorporados al marxismo, no parece -en mi opinión- que pueda sostenerse sin más, como hace Kelsen, que Marx adoptara la identificación hegeliana entre razón y realidad al menos en el sentido de pensar que un proceso caracterizado por la existencia de conflicto entre sus elementos integrantes constituye una contradicción lógica. Aunque ciertamente ni Marx ni los marxistas han mostrado en general mucha sensibilidad hacia la distinción entre mundo y lenguaje, no creo que pueda achacárseles el que cuando aluden a un conflicto (o, en su terminología, a una 'contradicción') entre clases sociales crean estar expresando una contradicción lógica. Ciertamente, puede reprocharse a los marxistas -como lo hace Popper- el que «gusten usar el término 'contradicción', allí donde sería menos engañoso usar términos como 'conflicto', 'tendencia opuesta', 'interés opuesto', etc.» ${ }^{153}$. Pero este reproche no es, en sí mismo, especialmente importante: cada cual usa los términos con la carga de significado que él mismo les asigna y, por otra parte, es frecuente en el lenguaje común el uso del término 'contradicción' con significados extralógicos: a nadie le causaría extrañeza que yo hablara, por ejemplo, de la existencia de una contradicción entre mi tendencia a la pereza y mi deseo de terminar este artículo. Si cabe enjuiciar negativamente el uso por parte de los marxistas, en contextos extralógicos, de términos que tienen «significados lógicos claros y bien definidos» ello obedece sólo a razones pragmáticas: a que este uso, como dice el mismo Popper, «ha contribuido considerablemente a la confusión de lógica y dialéctica que tan a menudo aparece en las discusiones de los dialécticos» ${ }^{154}$.

13.3 En opinión de R., Guastini, las obras kelsenianas de crítica del marxismo estarían lastradas por un cierto esencialismo lingüístico que residiría en el presupuesto -implícitamente operante, según Guastini, en estos textos de Kelsen- de que los términos capitales empleados en cualquier teoría del Derecho tendrían siempre la carga de significado atribuida a los mismos por la teoría pura. Este esencialismo implícito llevaría a Kelsen, siempre según Guastini, a una comprensión en buena medida distorsionada de los textos marxistas: pues, en su lectura de los mismos, tendería a «atribuir a las palabras significados no extraídos del contexto, sino importados de un lenguaje extratextual ya codificado (el lenguaje de la teoría pura del Derecho)»; se explicaría así que Kelsen «de la identidad de un lexema infiera acríticamente la identidad de un concepto» y que, por ello, «no perciba casi nunca las oscilaciones léxicas e indeterminaciones semánticas» ${ }^{155}$ presentes en las obras de los marxistas. Ejemplos de todo ello serían a juicio de Guastini, los siguientes: a) el entendimiento por parte de Kelsen del sintagma 'dicta-

153 K. R. Popper: ¿Qué es la dialéctica?, en Conjeturas y refutaciones, cit., p. 386.

154 Id.

155 R. Guastini: La dottrina pura del diritto e il marxismo, cit.. pp. 146-147. 
dura democrática' como necesariamente autocontradictorio, siendo así que, en alguno de los sentidos atribuidos por los marxistas al término 'dictadura' hablar de 'dictadura democrática' no implica caer en autocontradicción ${ }^{156}$; b) las críticas kelsenianas a los usos del término 'democracia' en los marxistas: «Kelsen -escribe Guastini- no percibe las ambigüedades semánticas y pragmáticas en los usos marxistas del vocablo 'democracia': Para él, 'democracia' no designa más que una forma de Estado, es decir, un particular modo o método, o procedimiento de creación del Derecho» ${ }^{157}$; c) el dato de que «frente a un enunciado que permite ser interpretado alternativamente o como proposición empírica, o como definición (estipulativa) Kelsen escoge, sin mayor análisis, la segunda alternativa» ${ }^{158}$ : tal es el caso de la tesis marxista acerca del Estado como organización del dominio de clase, que Kelsen interpretaría no como tesis de carácter empírico (de generalización inductiva) sino como proposición analítica ${ }^{159}$.

En mi opinión, la crítica de Guastini es desacertada en relación con los tres ejemplos por él suministrados: a) no es cierto que Kelsen entienda el sintagma 'dictadura democrática' como necesariamente autocontradictorio: ya vimos en el $\S 7$ cómo Kelsen subrayaba precisamente que «la conciliabilidad de la 'dictadura' en el sentido del uso lingüístico marx-engelsiano con la 'democracia' no puede ponerse en duda» ${ }^{16 \%}$; b) respecto a las críticas kelsenianas a los usos del término 'democracia' en los marxistas (y muy señaladamente en Lenin), el núcleo de las mismas se halla, en mi opinión, -como ya vimos en el § 2.2.2.-en poner de relieve cómo los desplazamientos de significado operados por los marxistas al respecto obedecen al propósito de aprovechar el prestigio del término 'democracia' -prestigio que proviene de designar en el uso común un determinado método de creación del orden jurídico- para legitimar contenidos normativos cuyo procedimiento de creación ha sido distinto del democrático: es decir, lo que Kelsen reprocha a los marxistas es que su desplazamiento del significado usual de 'democracia' no tenga más razón de ser que la de utilizar pro domo sua la emotividad favorable que este término suscita; c) por lo que hace a la tesis acerca del Estado como garante de la opresión de clase, ya vimos ampliamente en el $\S 5$ que Kelsen aborda la cuestión distinguiendo precisamente las dos alternativas de las que habla Guastini y adoptando una posición diferenciada respecto de cada una de ellas: si dicha tesis se interpreta como proposición empírica, Kelsen -como vimos- se muestra parcialmente de acuerdo con ella; si, por el contrario, se entiende como definición del término 'Estado', el desacuerdo kelseniano es radical: pues Kelsen rechaza que pueda ser conceptualmente adecuada cualquier definición de 'Estado' en términos funcionales.

Ello no obstante, sí hay, en mi opinión, en los escritos de Kelsen -aunque no donde lo quiere ver Guastini- tanto rastros de esencialismo

156 Id., p. 146.

157 Id., p. 167.

158 Id., p. 147.

159 Id., pp. 163-164.

160 S. y E., p. 320. 
en general, como, más en particular, momentos de críticas injustificadas al marxismo originadas por la proyección sobre él de las cargas de significado atribuidas a determinados términos por la teoría pura. Ejemplo de lo primero sería la negativa -de la que acabamos de ocuparnos en el $\S 13.2$.- a admitir posibles significados extralógicos del término 'contradicción'; de lo segundo, la crítica -que examinamos en el $\S$ 8.2.2.- al concepto de «Derecho revolucionario» como concepto autocontradictorio. Pues, en efecto, 'Derecho revolucionario' es una expresión autocontradictoria sólo si 'revolución' se entiende en sentido jurídico, esto es, como quiebra de la continuidad del ordenamiento, como cambio de norma básica. Si, por el contrario, el término 'revolución' se entiende -como sin duda lo entendía los marxistas que hablaban de 'Derecho revolucionario' - en sentido extrajurídico (aludiendo por ejemplo, a transformaciones profundas en las relaciones económicas y sociales) entonces la expresión 'Derecho revolucionario' no encierra, obviamente, autocontradicción alguna.

13.4. También el approach al Derecho propio de la teoría pura opera en algún caso, a mi juicio, como filtro deformador de la comprensión kelseniana de las posiciones marxistas: pienso especialmente en las críticas formuladas a la presencia de determinados dualismos en la teoría jurídica de Pasukanis. (cfr. $\S 11.3$ ). Kelsen, en efecto, no parece apercibirse de que la obra de Pasukanis trata de hacer frente un orden de problemas distinto de aquel al que responde la teoría pura: el jurista soviético no trata de construir un marco conceptual que posibilite la descripción libre de contradicciones de la estructura y de la dinámica del sistema jurídico como conjunto de normas válidas, sino que persigue más bien la elaboración de una teoría social del Derecho dirigida a la comprensión de la génesis histórico-económica y de las funciones sociales de lo jurídico ${ }^{161}$. Desde esta perspectiva, dualismos justamente criticados por Kelsen desde la óptica de un enfoque normativo, parecen requerir un tratamiento diferente: así, por ejemplo, si el derecho subjetivo puede y debe ser reconducido al Derecho objetivo desde el punto de vista de la fundamentación normativa, trasladar sin más esta misma reconducción al punto de vista de la génesis causal es probablemente disparatado: en este terreno, lo originario y lo derivado podrían ocupar en muchos casos (pensemos, por ejemplo, en la propiedad privada) posiciones justamente inversas a la que le son asignadas en el enfoque normativo. Análogamente, si para una teoría normativa puede ser fructífero identificar Estado y Derecho y considerar a aquél como una mera expresión hipostática para designar el conjunto del ordenamiento jurídico, esta misma identificación parece francamente descabellada si se traslada al plano de la descripción del funcionamiento real de los apartados estatales: pues traería como consecuencia que las actuaciones normativamente irregulares de esos aparatos estatales constituyeran un fenómeno literalmente impensable para el científico social.

13.5. Al margen de lo anterior, hay al menos dos puntos en los que cabe observar en Kelsen un evidente déficit de comprensión de las doctrinas

161 Sobre la diferencia de perspectiva entre Kelsen y Pasukanis, cfr. Norbert Reich: Hans Kelsen y Evgeni Pasukanis en Teoría pura del Derecho y teoría marxista del Derecho, cit.. pp. 21 y ss. 
marxistas. El primero de ellos se refiere a su entendimiento del materialismo histórico en términos de «interpretación económica de la sociedad» (cfr., por ejemplo, § 7.1.). Kelsen atribuye al marxismo una concepción según la cual en el nivel económico se alojaría la causa exclusiva (o, si se quiere, la esencia) de los procesos sociales, en tanto que los demás niveles de la estructura social (en la terminología marxista, la diversas superestructuras) constituirían meros efectos (o fenómenos) determinados por aquélla. Pues bien: no parece, desde luego, que tengan un contenido positivo preciso las fórmulas habitualmente empleadas por los marxistas al respecto, tales como las que aluden a la «autonomía relativa de las superestructuras» o a la «acción recíproca entre infraestructura y superestructuras»: lo así positivamente afirmado se resuelve en poco más que la trivialidad de que, en la sociedad, todo influye sobre todo, si bien la influencia de la economía es especialmente importante. Ello no obstante, estas fórmulas sí tienen un preciso alcance negativo: y éste es cabalmente el de excluir que la concepción materialista de la historia constituya una «interpretación económica de la sociedad» del tipo que Kelsen cree ver en ella.

Un segundo caso de clara incomprensión por parte de Kelsen afecta a las posiciones marxistas respecto a la relación entre Derecho igual y situaciones sociales desiguales. Kelsen parece pensar (cfr. § 10) que la opinión de los marxistas al respecto es que la teoría burguesa del Derecho presenta el Derecho burgués como un Derecho igual, siendo así que -a juicio de los marxistas- este Derecho sería un Derecho desigual, caracterizado por sancionar ventajas para las clases más favorecidas. La tesis sostenida por los marxistas -y repetida por ellos una y otra vez desde los pasajes clásicos de la Crítica del programa de Gotha de Marx hasta, pongamos por caso, los trabajos de U. Cerroni ${ }^{162}$-es, sin embargo, bien distinta: lo que los marxistas afirman es más bien que el Derecho burgués, precisamente en tanto que efectivamente es «Derecho formalmente igual», genera necesariamente desigual social, al otorgar un tratamiento formalmente igual a individuos socialmente ubicados en posiciones desiguales.

13.6. La obra de Kelsen sobre el marxismo presenta dos momentos de inconsistencia con postulados capitales de la metaética y de la teoría de la ciencia jurídica kelsenianas.

El primero afecta a la crítica al ideal de una sociedad anárquica: tal sociedad es, nos dice Kelsen, irrealizable (cfr. § 6.2.2.). Pero esta crítica, si asumimos la particularmente fuerte versión de la «gran división» que Kelsen hace suya, es por completo impertinente: pues nada perteneciente a la facticidad puede ser aducido en pro o en contra de un valor. El propio Kelsen, en un momento de mayor fidelidad a sus presupuestos metaéticos, escribe que «así como hay algo que sigue estando lleno de valor y sigue siendo digno de ser perseguido, aun cuando su realización deba manifestarse imposible, así también es indiferente -para el valor y la precisión de un finque su realización se presente como inevitable» ${ }^{63}$. Por otro lado, la crítica

162 Cfr., por ejemplo, U. Cerroni: Conocimiento científico y Derecho, en Introducción a la ciencia de la sociedad, Grijalbo, Barcelona, 1977, pp. 146 y ss.

163 S. y E., p. 180 (el subrayado es mío). 
al comunismo anárquico como ideal irrealizable nos muestra a un Kelsen al que -por incompatible que resulte con su rechazo radical de todo tipo de iusnaturalismo- cabría calificar de iusnaturalista mínimo: pues si bien la apelación a la naturaleza humana no permitiría justificar ningún contenido normativo determinado, la propia existencia de un ordenamiento coactivo sí encontraría su justificación en esa misma naturaleza.

Una segunda inconsistencia se presenta en relación con el análisis kelseniano del régimen soviético presidido por la constitución staliniana de 1936 (cfr. § 2.2.2). Este análisis concluye en la afirmación del carácter no democrático, sino despótico, del sistema de poder soviético; pero para poder llegar a esta razonable conclusión Kelsen ha debido ir más allá de la descripción de los preceptos constitucionales y penetrar en el funcionamiento efectivo del régimen staliniano: ha debido, pues, incurrir en un sincretismo metodológico prohibido por su teoría de la ciencia jurídica.

La puesta de relieve de estas inconsistencias no debe llevarnos, en mi opinión, a rechazar la crítica kelseniana al ideal anárquico ni, obviamente, su caracterización del Estado soviético como autocrático; lo que habría más bien que poner en cuestión es, por un lado, una concepción de la ciencia jurídica cuya aplicación estricta conduciría al dislate de considerar que la Unión Soviética stalinista estaba democráticamente gobernada y, por otro, la rigidez que la «gran división» tiene en Kelsen: pues, en efecto, para que un proyecto práctico pueda ser considerado valioso parece razonable situar como precondición que sea realizable, esto es, compatible con los datos factuales disponibles ${ }^{164}$.

13.7. Se ha señalado con frecuencia que el tratamiento dispensado al problema de la ideología constituye el aspecto más endeble de la crítica kelseniana al marxismo ${ }^{965}$. En mi opinión debe prestarse especial atención, a este propósito, a dos aspectos de la concepción kelseniana de la ideología: a) la completa ausencia de cualquier dimensión social-objetiva en la génesis de la ideología. Para Kelsen, la deformación ideológica tiene su origen en la interferencia de intereses o valoraciones subjetivas que distorsionan la representación del objeto de conocimiento; la matriz de la ideología es, pues, la presencia en la voluntad de un interés distinto del de conocer la verdad ${ }^{166}$ : la limpieza de la voluntad de todo interés distinto del de conocer asegura, así, la eliminación de la ideología. En este punto, me parece claro que las tesis marxistas sobre la determinación social de la ideología, sobre su origen

164 De distinta opinión es R. Guastini, quien considera que la única vía de crítica pertinente a los proyectos prácticos sería la propiamente valorativa (Cfr. La dottrina pura del diritto e il marxismo, cit., pp. 170 y ss.

165 Cfr., entre otros, F. Riccobono: Introduzione a TGD e m.s, cit.; P. Romer: La teoría pura del Derecho, de Hans Kelsen, como ideología y como crítica de la ideología, publicado como apéndice a Esencia y valor de la democracia, cit.; L. Tadic: Kelsen et Marx. Contribution au problème de l'idéologie dans «la théorie pure du Droit» et dans le marxisme, en A. Ph. D., n. ${ }^{\circ}$ 12: Marx et le Droit moderne, 1967.

166 «La ideología -leemos en la 2. ${ }^{\text {a }}$ ed. de la Reine Rechtslenre- encubre la realidad en cuanto, con el propósito de conservarla, defenderla, la transfigura, o, con el propósito de atacarla, destruirla o reemplazarla por otra, la desfigura» (Teoría pura del Derecho, trad. de R. J. Velnengo, UNAM, México, 1982, p. 122; los subrayados son míos). 
en el tejido objetivo de las relaciones sociales, han influido sobre las ciencias sociales contemporáneas -en particular, sobre la sociología del conocimiento- de forma más decisiva y también más fecunda que el -a este respecto- sumario y un tanto ingenuo enfoque kelseniano; b) la reducción de la ideología al ámbito del discurso descriptivo. Según hemos visto en el § 8.2.1. sólo en el lenguaje descriptivo cabe, en opinión de Kelsen, la deformación ideológica: pues si la falsedad es un elemento definitorio del concepto de «ideología», sólo podrán ser «ideológicos» los enunciados descriptivos, pero no aquellos otros cuyo significado es un juicio de valor, una norma o un mandato: de ahí que, en relación con el universo jurídico, «ideológico» sea un predicado que sólo puede ser aplicado con sentido a las teorías jurídicas (constituidas por enunciados descriptivos de normas) pero no al Derecho mismo (constituido por normas). A mi modo de ver, Kelsen plantea aquí un problema importante: ¿cómo podemos afirmar que la falsedad es un elemento constitutivo del concepto de «ideología» y al mismo tiempo predicar el carácter «ideológico» de sistemas de valores o de normas? ¿Es preciso que, para poder cohonestar ambas afirmaciones, atribuyamos valor veritativo a los valores y a las normas? El enfoque kelseniano conduce inexorablemente a una respuesta positiva: tan sólo podríamos decir que determinados valores o normas son ideológicos si entendemos que tales valores o normas son falsos (y, en consecuencia, que hay otros valores o normas que son verdaderos ). En mi opinión, sin embargo, no es necesario atribuir valor veritativo a valores y normas para poder predicar con sentido el carácter ideológico de los mismos: basta con que la falsedad connotada por el concepto de ideología la entendamos referida, no a los propios valores y/o normas, sino a los efectos de los mismos sobre las representaciones que de la realidad se hacen los que participan de los valores y/o se encuentran sometidos a las normas en cuestión. En este sentido, diríamos que el carácter ideológico del Derecho reside, no en que sus normas sean falsas, sino en que estas mismas normas provocan en los a ellas sometidos una representación falsa de las relaciones sociales: así podríamos sostener que instituciones tales como el contrato o el salario provocan que relaciones sociales en las que los hombres entran necesaria y desigualitariamente aparezcan, para estos mismos hombres, como relaciones presididas por la libertad y la igualdad entre las partes. Así reformulada, la tesis marxista sobre el carácter ideológico del Derecho permite, a mi juicio, una más cabal comprensión del Derecho como técnica social que la posibilitada por el enfoque kelseniano: pues si como hace Kelsen- se excluye al Derecho de la producción de ideología, el orden jurídico sólo puede ser pensado en su dimensión de técnica coactiva ${ }^{167}$ y queda por completo bloqueada la posibilidad de encarar su no menos importante dimensión de técnica de legitimación y de generación de consenso. 